\title{
Fungi in aquatic ecosystems
}

Hans-Peter Grossart (1) http://orcid.org/0000-0002-9141-0325, Silke Van den Wyngaert, Maiko Kagami https://orcid.org/0000-0003-3086-390X, Christian Wurzbacher, Michael Cunliffe 는 https://orcid.org/0000-0002-6716-3555, Keilor Rojas-Jimenez (i) http://orcid.org/0000-0003-4261-0010

DOI

10.1038/s41579-019-0175-8

Original publication date

12 March 2019 (First Online)

\section{Document version}

Author's accepted manuscript version

\section{Published in}

Nature Reviews Microbiology

\section{Citation}

Grossart H-P, Van den Wyngaert S, Kagami M, Wurzbacher C, Cunliffe M, Rojas-Jimenez K. Fungi in aquatic ecosystems. Nat Rev Microbiol. 2019;17(6):339-54. 


\title{
Fungi in aquatic ecosystems
}

\author{
Hans-Peter Grossart ${ }^{1,2}$, Silke Van den Wyngaert ${ }^{1}$, Maiko Kagami ${ }^{3}$, Christian \\ Wurzbacher $^{4}$, Michael Cunliffe ${ }^{5,6}$, Keilor Rojas-Jimenez ${ }^{7}$ \\ Author affiliations: \\ ${ }^{1}$ Dept. Experimental Limnology, Leibniz Institute of Freshwater Ecology and Inland \\ Fisheries, Alte Fischerhuette 2, D-16775 Stechlin, Germany \\ ${ }^{2}$ Dept. of Biochemistry and Biology, Potsdam University, Maulbeerallee 10, 14469 \\ Potsdam, Germany \\ ${ }^{3}$ Yokohama National University, Graduate School of Environment and Information \\ Sciences, Tokiwadai 79-7, Hodogaya-ku, Yokohama, 240-8502, Kanagawa, Japan \\ ${ }^{4}$ Dept. Urban Water Systems Engineering, Technical University of Munich, Am \\ Coulombwall 3, 85748 Garching, Germany \\ ${ }^{5}$ Marine Biological Association of the United Kingdom, The Laboratory, Citadel Hill, \\ Plymouth, Devon, PL1 2PB, UK \\ ${ }^{6}$ School of Biological and Marine Sciences, University of Plymouth, Drake Circus, \\ Plymouth, Devon, PL4 8AA, UK \\ ${ }^{7}$ Escuela de Biologia, Universidad de Costa Rica, 11501 San Pedro, San Jose, Costa \\ Rica
}

\begin{abstract}
Fungi are phylogenetically and functionally diverse ubiquitous components of almost all ecosystems on Earth, including aquatic environments stretching from high montane lakes down to the deep ocean. Aquatic ecosystems, however, remain frequently overlooked as fungal habitats, although fungi potentially hold important roles for organic matter cycling and food web dynamics. Within a broad ecological framework, we conceptualize the spatio-temporal dimensions, diversity, functions and organismic interactions of fungi in structuring aquatic foodwebs. We focus on currently unexplored fungal diversity, highlighting poorly understood ecosystems, including emerging artificial aquatic habitats. Recent methodological improvements have facilitated a greater appreciation of the importance of fungi in many aquatic systems, yet a conceptual framework is still missing. To date, aquatic fungi and their interactions have largely remained "hidden" and require interdisciplinary efforts to be explored in an ecosystem context. There remain obvious methodological and knowledge gaps to explore potential functions of aquatic fungi, moving from the microscale to the global scale. This knowledge is urgently needed since we humans strongly interfere with structure and function of natural ecosystems by permanently reshaping most of the Earth's surface and creating vast areas of novel urban habitats.
\end{abstract}




\section{Introduction:}

Recent advances in DNA sequencing technology have revealed that fungi are abundant in many, if not all aquatic ecosystems, however their diversity, quantitative abundance, ecological function and, in particular, their interactions with other microorganisms, remain largely speculative, unexplored and missing from current general concepts in aquatic ecology and biogeochemistry ${ }^{1-4}$. This is surprising since terrestrial-focused research has understood the outstanding ecological role of fungi for $>100$ years, and therefore fungi constitute a major component of general concepts in terrestrial science ${ }^{5,6}$. In aquatic ecosystems, the systematic analysis of fungal diversity and their ecological roles has faced several setbacks due to methodological limitations and a too small scientific community, in particular in the marine environment ${ }^{7-11}$.

This review focusses on aquatic fungi, which form a morphologically, phylogenetically, and ecologically diverse group ${ }^{7}$. We here broadly define "aquatic fungi" as fungi that rely for the whole or part of their life cycle on aquatic habitats (FIG. 1). Three groups (indwellers, periodic immigrants and versatile immigrants) based on their degree of adaptation and dependence on aquatic habitats have been previously defined ${ }^{12}$. We highlight the numerous knowledge gaps in their diversity, interactions and functional roles, as well as methodological limitations. In this review we propose new research avenues to set aquatic fungi in a broad ecological framework. Here, we do not explore the many existing gaps in the fungal phylogenetic tree.

In aquatic systems, fungi constitute a significant proportion of eukaryotic sequences (section 2.1) ${ }^{13-15}$. However, there is almost no information available on their quantitative abundance, i.e. comparing the proportion of fungal biomass with total eukaryotic biomass. The only reliable information on fungal biomass exists from studies on litter degradation, mainly leaf litter in running waters ${ }^{16}$. There, higher fungi dominate over bacteria in terms of biomass, production and enzymatic substrate degradation. Direct counts suggested that fungal biomass typically contributed 90$95 \%$ to the total microbial biomass during early stages of leaf decay, confirming earlier conclusions on the ecological importance of aquatic fungi ${ }^{16}$. More recently, measurements of ${ }^{13} \mathrm{C}$ isotope enrichments in all identified PLFAs revealed that the fungal biomass was up to 10 -fold higher than for bacteria ${ }^{17}$. Using the same method, the fungal biomass proportion in the pelagic zone of numerous lakes and kettle holes in northeast Germany was quantified ${ }^{18}$. In contrast to leave litter, in the pelagic zone, bacteria generally dominated microbial communities, and fungi in average accounted for solely $9.2+5.2 \%$ of all PLFAs in seston biomass.

To our knowledge, there is no study available which has precisely quantified the fungal contribution to microbial respiration, mainly because current respiration methods measure total microbial respiration, and cannot distinguish between the proportion of different microorganisms such as algae, fungi and bacteria. Currently, there is a great need to determine more precisely fungal activities to explore the role of fungi in aquatic food webs. Generally, there is little information on fungal activities, predominantly from leaf litter studies in flowing water systems. Comparing numerous studies simultaneously measuring ${ }^{14} \mathrm{C}$-acetate incorporation into ergosterol (fungal hyphomycetes biomass production) and ${ }^{14} \mathrm{C}$-leucine or ${ }^{3} \mathrm{H}$-thymidine into bacterial proteins or DNA, respectively (bacterial biomass production), revealed that on leaf litter fungal production rates often greatly exceed those of bacteria ${ }^{16}$. Repeated measurements of fungal biomass production and their standing stock on leaf litter estimated an annual fungal production of 16 to $193 \mathrm{~g} \mathrm{~m}^{-2}$ from which up to $\geq 50 \%$ can 
be channelled into microscopically identifiable conidia of aquatic hyphomycetes (see references in REF. ${ }^{16}$ ).

Molecular studies, however, revealed that fungal taxa in aquatic systems often comprise taxa other than aquatic hyphomycetes (e.g. REF. ${ }^{19}$ ). These aquatic fungi have emerged as an important source of "microbial dark matter" whose composition and ecology are largely unknown, although their existence is inferred from molecular data $^{20}$. It is estimated that fungi can hold the potential to largely affect aquatic foodweb structures, stability and functionality through syntrophic to parasitic interactions with other organisms and organic matter $(\mathrm{OM})^{21-23}$. However, for most aquatic ecosystems, little is known about how fungal interactions will affect vital ecosystem functions such as the efficiency of the oceanic carbon pump (carbon pump refers to the mechanism by which atmospheric carbon is sequestered by vertical transfer to deep waters and sediments) and ecosystem health ${ }^{24}$. Consequently, it is urgent to extend our knowledge on diversity and ecology of aquatic fungi, to better understand ecosystem feedback mechanisms to climate and anthropogenic change ${ }^{10}$. This knowledge is crucial to reliably project future developments and sustainably manage almost any aquatic ecosystems on Earth.

Currently, aquatic organisms and ecosystems face a "post-stability-era" with increasing intensity of short-term and long-term anthropogenic disturbances. Shortterm disturbances are pulsed event based disturbances, whereas long-term disturbances comprise gradually increasing press disturbances such as global climate change or urbanization both leading to species loss and shifts in community composition. Many novel and hidden interactions between aquatic fungi and other foodweb components await the discovery and recognition in a holistic ecosystem and landscape context. This review aims to integrate, in a broad framework, knowledge and gaps about fungal diversity, habitats, interactions, and functions, and provides a conceptual framework for aquatic fungi in natural and artificial aquatic environments by integrating fungal processes and their consequences for the functioning of various aquatic ecosystems.

\section{Under-explored diversity of aquatic fungi}

In analogy of the existence of "dark matter" in the universe, microbiologists have recently uncovered a high diversity of taxa, which are called "microbial dark matter" 25 . So far, it has been only detected by molecular tools, mainly for prokaryotes $^{25-27}$, but also increasingly for eukaryotic microorganisms ${ }^{28}$, including fungi ${ }^{20}$ termed "dark matter fungi". Although not yet isolated into culture, these organisms may be highly abundant and dominate natural ecosystems ${ }^{29}$. In TABLE S4 of $\mathrm{REF}^{30}$ it is obvious that most fungi in a large number of lakes and ponds in northeast Germany are uncharacterized and hence unknown. A similar pattern has been also found by another study exploring biogeographical patterns and biases of fungal diversity ${ }^{31}$. Targeted isolation approaches have started to reveal that some of these novel lineages within the early diverging fungi represent parasitic fungi of phytoplankton $^{32,33}$. In comparison with terrestrial and wetland fungi, the exploration and knowledge of most aquatic fungi and their ecological function remain limited ${ }^{8,34}$ and often focussed on specific habitats predominantly in flowing water (i.e. lotic) ecosystems.

Studies are still insufficient or lack the adequate spatial and temporal resolution on fungal communities in marine and freshwater systems considering, for example, different latitudinal zones, ecosystems (water column and sediments), marine snow, and extreme environments such as deep sea vents. In contrast to global 
fungal studies in soil ecosystems ${ }^{35,36}$, studies on aquatic fungi have mostly addressed distribution patterns at the regional scales (e.g. river basin ${ }^{37}$, Scandinavian lakes ${ }^{31}$, or ocean basin ${ }^{38}$ ). Relatively recently, large-scale public datasets such as the International Census of Marine Microbes, the Tara Oceans Expeditions or the Earth Microbiome Project have become available, enabling a new era of analysing global drivers of, e.g., marine fungi ${ }^{39,40}$. These studies become increasingly powerful with the advancement of sequencing technology, i.e. moving from short reads (i.e. 454pyrosequencing and Illumina Amplicon sequencing) to long reads (full length of the nuclear ribosomal small subunit or even whole genomes retrieved from metagenomes; PacBio or Oxford Nanopore). For aquatic hyphomycetes, a global set of data on fungal taxa published between December 1942 and October 2014 including those available in the "Web of Science" database, as well as others in national journals, theses and taxonomic guides has been used for a global analysis ${ }^{41}$.

The advancements in sequencing technologies have stimulated a new wave in research of aquatic fungi. In particular, molecular-based detection of marker genes revealed novel fungal biodiversity in the aquatic realm that was new to science, ${ }^{9,42}$ and opened up a new black box of known unknowns ${ }^{20}$. As the "fungal dark matter" is slowly becoming more visible, there is a large potential to discover new fungal lineages, particularly associated with early diverging lineages at the base of the fungal tree, e.g. Chytridiomycota and Rozellomycota ${ }^{13,43-45}$. In particular, the latter is hyperdiverse and poorly known, which requires new explorative approaches such as single cell genome sequencing ${ }^{47}$. This will allow for a better understanding of the evolution of the entire fungal kingdom.

DNA databases are increasingly populated with sequences for which little or no morphological and functional information is available, leading to an increasing gap between well annotated reference data and "dark matter DNA sequences". This 'annotation gap' does not only affect functional genes, but is even clearly visible in curated fungal barcode reference data. Currently, attempts have been made towards unifying all ribosomal regions into one single ribosomal fungal marker that covers all of the eukaryotic ribosomal regions at once ${ }^{30,47}$, which greatly improves taxonomic resolution of non-cultured and unknown fungi. However, we want to highlight that there is a great need for increased cultivation of fungal strains both for phylogenetic and physiological characterization which allows for linking phylogenetic, morphological as well as physiological features in a reliable manner.

\section{Fungal habitats}

\subsection{Natural habitats}

For a long time, it was believed that the diversity and abundance of fungi in aquatic ecosystems was relatively low ${ }^{7,48}$. Recently, however, a large number of studies in different habitats of freshwater and marine environments have proved otherwise, indicating that aquatic fungi can be one of the most abundant groups of eukaryotes in aquatic ecosystems. Particularly in freshwater, fungi can reach relative abundances of more than $50 \%$ of all eukaryotic sequences. In other habitats, such as some saline habitats, abundances are low, i.e. below $1 \%{ }^{42,49-51}$. Thus, fungal proportion of all aquatic eukaryotes can be extremely variable and depends on the respective ecosystem and its environmental settings.

The first morphological characterizations of aquatic fungi in the mid-1 $9^{\text {th }}$ century were carried out in ponds, lakes, rivers and streams using rudimentary microscopes $^{52}$. In spite of the methodological limitations of the time, first detailed 
descriptions of zoosporic freshwater fungi were made, for example of the genus Chytridium, one of the first parasitic phytoplankton fungi known ${ }^{52}$. Subsequent technological advances in microscopy allowed better morphological characterizations and hence descriptions of multiple species of Phycomycetes and Hyphomycetes colonizing the mulch of streams, estuaries and coastal areas including genera such as Tetracladium, Cercospora, and Ophioceras ${ }^{53-56}$.

A large number of aquatic habitats have been identified in which fungi grow and thrive. In FIG. 2, we illustrate the state of current knowledge of diversity, functions, interactions, and ecological role of aquatic fungi in diverse natural habitats ranging from mountain peaks to the depths of the oceans. Further, we also display their relationship with environmental gradients of altitude, depth, atmospheric pressure, particulate organic matter, and nutrients. In TABLE 1, we provide an overview on the predominant taxonomic groups and common genera found in these habitats. Generally, most studies have used cultivation-dependent and -independent techniques including next generation sequencing to explore the diversity and abundance of fungi in aquatic habitats. Despite these efforts, FIG. 2 illustrates that there is still little knowledge of fungi in most aquatic ecosystems and even less of their functions, interactions, and ecology. There is a great need to quantify with greater precision their abundances (e.g. using qPCR) and particularly their biomass as well as production rates. A better determination of these fungal key features is essential to quantify the participation of fungi in aquatic food webs and carbon cycle. Yet, such studies are hampered by current limitations in methodological approaches.

Through the use of cultivation-dependent techniques, several species of filamentous fungi and yeasts (aerobic and fermentative forms) have been isolated from numerous natural habitats. Some of the predominant genera in aquatic ecosystems include Aspergillus, Penicillium, Cladosporium, Aureobasidium, Cryptococcus, Malassezia, Candida and Rhodotorula, which have been isolated from such contrasting ecosystems as the deep-sea ${ }^{57-61}$, subsea floor ${ }^{62-64}$, hydrothermal vents $^{65-67}$, marine coastal waters ${ }^{68,69}$, lakes ${ }^{70-71}$, ice and snow ${ }^{72-74}$ as well as other freshwater and brackish ecosystems ${ }^{7,48,75}$.

The use of cultivation-independent methods confirmed, in some cases, the predominant groups determined via cultivation techniques, particularly in habitats such as marine sediments ${ }^{61,69,76,77}$, aquifers ${ }^{78,80}$, and polluted aquatic environments ${ }^{81-}$ ${ }^{83}$. However, high-throughput sequencing has allowed the scientific community to unravel an enormous diversity and abundance of aquatic fungi in most natural habitats previously hidden ${ }^{20}$. Many of these unknown fungi belong to early divergent lineages of Rozellomycota and Chytridiomycota, where LKM11, Rhizophydium and Lobulomyces represent some of those abundant taxa with references in current databases. These uncharacterized fungi, sometimes called "dark matter fungi", have been shown to dominate fungal communities in large parts of aquatic ecosystems on Earth, including temperate freshwater lakes ${ }^{9,42,49,84-88}$, coastal and marine environments $^{11,89-92}$, snow $^{93}$, and polar aquatic systems ${ }^{50,5194,95}$.

At present, we witness an exciting resurgence of interest in aquatic mycology. There is a greater availability of sophisticated microbial techniques allowing to access virtually any organism and ecosystem on the planet. The deciphering of that universe of unknown fungi present in the great variety of natural and artificial aquatic habitats has just begun. 


\subsection{Artificial habitats}

Humans continue to increase the generation of novel aquatic habitats such as street gutters, water pipes, sewage systems, wastewater treatment plants, reservoirs for cooling power plants and storing waste, etc., which are readily colonized by microbes including a broad variety of fungi (FIG. 3, TABLE 1). Understanding the microbiome of the built environment is still in its infancies, however, will rapidly gain importance in a more urbanized world ${ }^{96}$. Culture independent fungal studies on tap water, bathroom or shower pipes are still rare (e.g., REF. ${ }^{97}$ ) and thus we know very little on fungal biodiversity in these semi-closed systems, besides typical indoor fungi that are associated with moisture ${ }^{96}$. Aquatic fungal communities of infrastructures are until now little investigated and next to the most obvious lentic-like habitats of garden and irrigation ponds, reservoirs, pools, puddles, tree holes, fountains or aquaria, new interesting habitats emerge. For instance, we know that potentially "dark matter fungi" reside in intermittent aquatic autotrophic street gutter biofilms ${ }^{98}$, but, enormous knowledge gaps exist on a large spatial scale including many hidden urban habitats, such as street runoff systems and complete sewer networks.

The probably best described urban fungal habitats are wastewater treatment plants (e.g., REF. ${ }^{99}$ ). A multitude of recent studies confirmed next to fermentative yeasts a dominance of "dark matter fungi" (mainly Rozellomycota), often in the anaerobic, biofilm dominated stages ${ }^{100-104}$. Their function in wastewater processing is unclear, and it will be highly interesting, if "dark matter fungi" have the same potential for biotechnologies than higher fungi (e.g. REF. ${ }^{105-107}$. Similarly, microalgae reactors and open ponds for algal compound production (e.g. biofuels) are economically important new habitats, were parasitic fungi can have detrimental effects on the productivity ${ }^{108,109}$. Algal mass cultures provide habitats for parasitic fungi including chytrids and aphelids ${ }^{110-112}$. On the other hand, animal aquacultures are more dominated by fungal-like parasites (oomycetes), and yet it is unclear if "dark matter fungal groups" other than microsporidian parasites play a substantial functional role $^{113,114}$. Hydroponic systems for plant and animal cultivation represent other economically important habitats, in which fungal mycorrhiza (mycorrhiza depicts the symbiotic consortium of a fungus and the roots of its vascular host plant) and fungal pathogens are in the focus of current research, while we know very little on emerging aquaponic systems ${ }^{115}$, which include simplified pond-like aquatic foodwebs.

There are numerous man-made extreme aquatic habitats such as biogas reactors ${ }^{116}$ or even nuclear reactors ${ }^{117}$ for which little is known about fungal diversity and function. Consequently, most of engineered or constructed aquatic systems and urban ecosystems comprise largely unexplored fungal habitats. For the coming years, we foresee a growing interest in studying diversity, function and ecological role of aquatic fungi in urban and man-shaped environments. Furthermore, humans continuously introduce terrestrial matter and waste products such as microplastics and other anthropogenic debris into natural aquatic ecosystems in an unprecedented scale. These pollutants can represent new artificial surfaces for colonization of fungal communities ${ }^{118}$, whose diversity and structure are different from the natural assemblages ${ }^{119}$. These novel habitats are provoking the development of complex interactions between autotrophic and heterotrophic organisms, with profound consequences for functionality and evolution of aquatic ecosystems ${ }^{120}$, e.g., via gene exchange of functional genes. Thus, the rapid increase in a multitude of artificial fungal habitats implies extensive, yet unknown human interferences with the natural environment and the potential to change key components and functions of aquatic ecosystems worldwide. 


\section{Interactions between fungi and other organisms}

The large proportion of "unknown" fungal diversity and functions implies an even larger number of hidden interactions that still await discovery (FIG. 4, BOX 1).

\section{Box 1: Biotic interactions with aquatic fungi}

The outcome of ecosystem processes is governed by a complex network of direct and indirect interactions between organisms. Within this interaction network, the genetic, morphological and functional diverse aquatic fungi play multiple roles, engaging in both negative (antagonistic) as well as positive (synergistic) interactions with virtually all members of the aquatic community. This box gives a brief overview providing some examples of the multitude of possible interactions between aquatic fungi and various foodweb components:

\section{i) Fungi-virus}

Mycoviruses have been relatively well studied in endophytic and phytopathogenic fungi, where they play both mutualistic and antagonistic roles in complex interactions between fungi and host plants ${ }^{121}$. Recently, virus and plasmid symbionts were detected in a collection of marine fungi isolated from the seagrass Posidonia oceanica $^{122}$. Yet, the ecological effects of aquatic mycoviruses are almost entirely unknown and remain to be elucidated.

\section{ii) Fungi-prokaryotes}

Antagonistic interactions between fungi and prokaryotes are widespread and several studies have shown inhibition of bacterial growth by aquatic hyphomycetes ${ }^{123}$. Vice versa, antifungal producing bacteria associated to the skin of amphibian hosts, have been found to inhibit the growth of the pathogenic amphibian chytrid fungus Batrachochytrium dendrobatidis ${ }^{124}$. Antagonism between bacteria and fungi has been shown to be often connected to direct resource competition ${ }^{125}$. Recently, even direct trophic interactions between the largest freshwater bacterium Achromatium and chytrid fungi have been observed ${ }^{126}$ (FIG. 4). Antagonism between fungi and bacteria seem to be more prevalent, although synergistic effects have also been demonstrated $^{127,128}$. A recent review ${ }^{129}$ highlights the ecological importance of fungiprokaryotes interactions as significant drivers of many ecosystem functions and organismic health ("metaorganism concept"). Much is known about the complex mechanisms of these interactions in terrestrial ecosystems, but for aquatic ecosystems these interactions are still largely unknown ${ }^{40}$.

\section{iii) Fungi-heterotrophic protists}

Fungi can be both predators/parasites and prey of heterotrophic protists. Amoebophagous fungi for example have been described from all major fungal groups: Basidiomycota, Ascomycota, Zygomycota, Chytridiomycota and Cryptomycota ${ }^{130}$. Zoosporic fungi have been found to be parasitic as well as serving as food source for Heliozoa ${ }^{131}$. Although fungi-protist interactions have gained great interest in research on rumen fluids ${ }^{132}$, rice fields ${ }^{133}$ or soil ecosystems ${ }^{134}$ yet, these interactions have gained little attention in aquatic systems.

\section{iv) Fungi-fungi-like organisms}

Zoosporic true fungi (e.g. Chytridiomycota) and fungi-like protists belonging to the kingdom Chromista (e.g. Oomycota, Hyphochytriomycota, Labyrinthulomycota) resemble in their ecological life styles and can occupy similar ecological niches ${ }^{135,136}$. As parasites they often share the same phytoplankton host species ${ }^{137,138}$ and as saprotrophs they can utilize similar OM, e.g. pollen, zooplankton carcasses ${ }^{139}$. In 
terrestrial ecosystems interactions between pathogenic fungi and oomycetes and their consequences for the development of plant disease has been recognized ${ }^{140}$. In aquatic ecosystems our knowledge remains restricted to descriptive studies on their cooccurrence on similar hosts/substrates, whereas studies investigating direct ecological interactions between true fungi and fungi-like protists and their consequences for OM transformation are completely lacking.

\section{v) Fungi-primary producers}

Zoosporic fungi are well known as parasites of freshwater and marine phytoplankton $^{23}$ and mutualistic symbiosis are rare exceptions ${ }^{141}$. Other antagonistic interactions such as allelopathic interactions between diatoms and aquatic hyphomycetes fungi have been demonstrated to negatively affect primary production in biofilms ${ }^{142}$. In contrast, mutualism is the predominant life form of aquatic lichens in freshwater and marine ecosystems ${ }^{143}$, yet rather little is known about their ecological role. "Engineered" mutualism has been established between C. reinhardtii, the yeast Saccharomyces cerevisiae, and filamentous Ascomycota ${ }^{144}$, which increases biomass productivity. In the water tanks of bromeliads, diverse yeast communities are present and display a wide variety of extracellular enzymatic activities which can promote plant growth by increasing nutrient availability and absorption ${ }^{145}$. For natural aquatic systems, however, there are only very few reports on such interactions. This is also true for studies on fungal interactions with aquatic macrophytes, which are severely limited by comprehending the scope and functionality of the association of arbuscular mycorrhizae and endophytes with this group of plants ${ }^{146,147}$. Thus, many questions remain how fungi affect and interfere with the basis of aquatic foodwebs and thus shape foodweb structure and the flow of energy and organic matter through aquatic ecosystems.

\section{vi) Fungi - Fungi}

Mycoparasitism, i.e. fungi parasitizing on other fungi, has been frequently described $^{148}$. Rozellomycota can be parasites or hyperparasites of chytrid fungi ${ }^{149}$. The hyphomycete Crucella subtilis forms hyphal branches around the hyphae of several species of aquatic hyphomycetes and thus negatively affects early colonization and sporulation of the hyphomycete Anguillospora filiformis ${ }^{150}$. Although several examples have been found in aquatic ecosystems, their consequences for aquatic foodweb structure and dynamics remain largely unknown.

\section{vii) Fungi- animals}

The pathogenic chytrid Batrachochytrium dendrobatidis is an important factor for the worldwide decline in amphibian populations ${ }^{151}$. Invertebrates (e.g. zooplankton) also constitute common hosts and occasionally prey for a variety of fungal parasites, i.e. microsporidia, yeast, and chytrids, which hold different levels of virulence in their respective hosts ${ }^{152,153}$. Evidence for detrimental and beneficial interactions between fungi and the holobiont of marine sessile invertebrates such as corals, sponges, ascidians has been well reviewed ${ }^{154}$. Coelomomyces psorophorae constitutes an example of a fungal parasite that uses differently sized invertebrate hosts, i.e. the malaria mosquito and a Copepod host, to complete its life cycle ${ }^{155}$. On the contrary, fungi can serve as prey for aquatic invertebrates, i.e. fungal mycelia contribute substantially to the diet and growth of aquatic shredders, whereas fungal zoosporic propagules rather serve as a food supplement of zooplankton ${ }^{156,157}$. An alternative form of interactions is represented by Trichomycetes, which display a diverse ecological group of obligate endosymbionts, including Zygomycota fungi, in the gut of many aquatic insect. Relationships between these gut fungi and their hosts range from mutualistic to parasitic, largely depending on environmental conditions ${ }^{158}$, 
though these fungi are more generally regarded as commensalists ${ }^{159}$. Consequently, fungi-animals interactions can range from parasitism to symbiosis, and fungi can provide food for various aquatic animals. Yet, most of these interactions and their ecological consequences remain to be explored.

With the increasing number of available studies on aquatic systems, it is now possible to also perform meta-analyses. For example, REF. ${ }^{15}$ generated hypotheses about fungal interactions with other members of the foodweb, and confirmed the central but yet unexplored role of fungal interactions in freshwater ecosystems. Symbiotic relationships are greatly unknown and difficult to study because of their microscopic scale, community complexity and intricate nature. Early diverging fungi ${ }^{160}$, which comprise most of the "dark matter fungi" ${ }^{20}$, have been frequently found to establish parasitic and symbiotic interactions with other aquatic organisms. However, the phenotypic distinction between early diverging fungi and fungi-like protists is often impossible hampering detection, and making studies of their specific interactions only possible using molecular-based methods or co-occurrence based statistics.

The largely unknown fungal interactions indicate that inferring the nature of fungal interactions in situ is not always trivial. Phytoplankton associated chytrids present an example where mutualistic, saprophytic or parasitic relationships can be hard to distinguish ${ }^{161}$. Moreover, fungal life styles and interactions are not static but often present a highly dynamic continuum that is context dependent ${ }^{162}$. Spatial and temporal variations in local selection and gene flow create complex geographic mosaics of coevolutionary hot and cold spots, which can lead to highly divergent species interactions across geographic scales ${ }^{163}$. Spatial connectivity and dispersal play central roles in the coevolutionary dynamics of species interactions by connecting populations and communities in a landscape context (i.e. metacommunity concept). Currently, we know very little about dispersal potential and population structure of aquatic fungi ${ }^{164}$ and how this potentially reshapes interactions across different spatial and temporal scales.

Fungal parasite-phytoplankton interactions, for example, have been mainly studied at the population and community level, considering aquatic habitats as spatially isolated and closed systems, thus studies that include spatial connectivity and metacommunity interactions on an ecosystem level are urgently required.

Additionally, studies and modelling exercises are extremely challenging since there are multiple fungal parasites competing for the same host ${ }^{86}$, cryptic diversity of hosts and fungal parasites ${ }^{33}$, and even hyper-parasites of fungal parasites ${ }^{165,166}$. Moreover, very little is known about the interactions of these parasitic fungi with bacteria, or heterotrophic protists acting as potential grazers ${ }^{1}$.

The interpretation of the nature of fungal interactions is not always straightforward, particularly when considering different temporal, spatial and environmental contexts and current climate and anthropogenic changes. Despite this, recent metabarcoding and metagenomic studies of pelagic habitats of lakes ${ }^{88,167}$ and oceans ${ }^{14,49,50}$ found a rich diversity of parasitic, (or facultative parasitic) zoosporic fungi associated with phytoplankton and zooplankton ${ }^{23,168,169}$. In this regard, several authors ${ }^{2,8,170,171}$ confirmed that fungal parasites on planktonic organisms constitute the rule rather than the exception. Thus, we suggest that the role of fungal parasites in structuring aquatic foodwebs can be equally important as shown for other planktonic parasites $^{8,172}$. 


\section{Aquatic fungi in a foodweb and landscale context; spatio-temporal processes of organic matter $(\mathrm{OM})$ processing}

The current methodological advancements both of culture-independent and dependent tools (see section 5), for the first time, allow studying aquatic fungal communities in a more holistic and overarching manner. We propose to consider the "aquatic mycobiome" in an entire landscape context, following the global water cycle, i.e. water flowing via streams and rivers from the mountains through lakes and wetlands into the ocean (FIG. 2). Moving through the landscape, water carries inorganic and $\mathrm{OM}$ in a temporally dynamic manner from the adjacent land constantly reshaping microbial communities and the corresponding metabolic demands. Due to their unique enzymatic capabilities and metabolic versatility ${ }^{173}$ aquatic fungi form important components of the global aquatic carbon and nutrient cycle ${ }^{10}$ and may provide feedbacks to changes in global climate and anthropogenic activities. In particular, increasing urbanization and other anthropogenic landscape use will greatly affect functionality of microbial communities and their impact on biogeochemical cycles including the, so far, largely unexplored ecological role of aquatic fungi. Up to date, little is known about the ecological role of fungi in aquatic foodwebs, particularly in a more holistic manner stretching across various spatial and temporal gradients in a large-scale or global perspective. This knowledge gap is a further unknown of the global mycobiome.

\subsection{Fungi in open water (lakes and oceans)}

As described in chapter 3, there is a high degree of unknown fungal interactions among almost all components of the aquatic systems, with often unspecified ecological consequences for foodweb dynamics and functions (Figure 5). In freshwater ecosystems, it has been described that hyphomycetes fragment litter, thus generating fine particulate organic matter ${ }^{174}$, but little is known about the role of aquatic fungi in the transformation of other OM aggregates in rivers, lakes, and oceans ${ }^{175}$. Parasitic fungi, for example, may lead to disintegration of planktonic species with negative consequences for sinking fluxes ${ }^{176}$, while there is limited knowledge about the role of saprophytic aquatic fungi in processes such as transformation of carbon in lake or marine snow ${ }^{177}$. In marine systems, saprotrophic mycoplankton can utilize algal polysaccharides, indicating that aquatic fungi can affect the flow of OM in multiple, but poorly understood ways ${ }^{178}$.

Furthermore, parasitic fungi such as chytrids efficiently utilize "living" phytoplankton OM and have the ability to change quality and quantity of phytoplankton-derived OM, which not only feeds back to higher trophic levels such as zooplankton ("Mycoloop", FIG. 5), but also to the microbial loop ${ }^{128}$. Since saprotrophic fungi also utilize phytoplankton derived $\mathrm{OM}^{11}$, the questions arise whether and how they compete with parasitic fungi and heterotrophic bacteria for DOM or POM, and whether this affects microbial foodweb dynamics and thus OM fluxes? This knowledge gap comprises several pelagic OM transformation pathways mediated by aquatic fungi such as phytoplankton lysis, OM aggregation, and disintegration. Therefore, we use the term "Mycoflux" (FIG. 5), which refers to hidden fungal interactions, their ecology and effects on the aquatic carbon pump.

\subsection{Benthic recycling}

Aquatic fungi have been early recognized as major recyclers of coarse plant materials in streams, sustaining a detritus-based foodweb ${ }^{174,175}$. Also, associations between fungi and phytoplankton, especially diatoms, have been reported in benthic 
habitats such as tidal flats ${ }^{179}$ and under the Arctic ice ${ }^{94}$. In the benthic environments of lakes, it has been demonstrated that leaf-colonizing fungi have the potential to improve the palatability of litter for macrozoobenthos grazers ${ }^{175,180}$. Furthermore, it has been shown for leaf litter that fungi, in particular hyphomycetes, upgrade the nutritional value of leaf litter, e.g. by lowering C:N:P ratio (reviewed by REF. ${ }^{16}$ ). Fungi-mediated changes in organic matter stoichiometry have also been described in other systems, e.g. in bromeliad ecosystems ${ }^{145,181}$. In benthic systems, this specific pathway, termed "benthic shunt, allows to efficiently channel refractory OM up to higher trophic levels, e.g. fishes ${ }^{180}$, in which the fungal participation depends largely on the quality and type of $\mathrm{OM}^{17}$ (FIG. 5). The benthic shunt has not been explicitly described for marine ecosystems, although a similar mechanism can be expected, since marine fungi can colonize and degrade organic litter, such as sea grass and kelp ${ }^{182}$. These recent discoveries, together with the still in progress discovery of "dark matter fungi" in open waters ${ }^{49,50}$, suggest that fungi play an important, but largely neglected, role in aquatic biogeochemical cycles.

\subsection{Spatial patterns}

All freshwater and marine habitats (e.g., rivers, lakes, coastal and open oceans, sea ice, hydrothermal vents, deep sea sediments) are to a various degree linked to each other (TABLE 2), and differ greatly in specific habitat characteristics and OM availability. Consequently, we can expect morphologically and functionally highly diverse fungal communities, differing mainly by the degree of connectivity and the specific characteristics of the habitat ${ }^{183}$.

In analogy to the river-continuum concept ${ }^{184}$, we propose that fungal community structure, functions and the ecological role change with the flow of water through the landscape and the degree of the aquatic-terrestrial coupling (FIG. 2). The flow of water follows numerous gradients such as altitude, water depth/pressure, water residence time, carbon sources (dissolved OM, fine and coarse particulate OM (DOM, FPOM and CPOM, respectively)) and age (generally older from terrestrial and younger from aquatic sources) as well as salinity (FIG. 2). These gradients connect and shape the respective fungal habitats along its path greatly controlling the availability of fungal substrates (dissolved OM, CPOM, and FPOM). Thus, we consider the aquatic mycobiome as a function of the intrinsic features and connectivity of the respective aquatic ecosystems ${ }^{185}$. In this scenario, the fungal species turnover is structured accordingly, influencing the presence and abundance of size-dependent saprophytes (e.g., aquatic hyphomycetes as consumers of CPOM, chytrids as consumers of FPOM), yeasts (as consumers of DOM), and parasites (as consumers of living OM).

For example, in high altitude, alpine flowing water systems, $\mathrm{OM}$ is to a large extent supplied by snow and ice melt runoff from the surrounding terrestrial ecosystem of a well-defined and relatively small catchment basin. In these high flow velocities systems, most of the microbial activity takes place in microbial biofilms ${ }^{186}$ and thus we can expect that fungi are mainly situated in biofilms, able to degrade the terrestrial and algal OM. In contrast, high-altitude alpine lakes comprise an unexpected richness in Chytridiomycota and thus presumably a large proportion of parasites of phytoplankton ${ }^{187}$. These examples suggest a close coupling between autotrophs and fungi and an important role of fungal parasites for foodweb structure in these oligotrophic and cold lentic systems.

Further downstream, rivers exhibit lower flow velocities and receive a greater extent of fresh terrestrial DOM and CPOM such as leaves and an increasing fraction 
of autochthonous, relatively labile OM. As a consequence, OM pools greatly diversify forming a more diverse, mixed, and pelagic fungal community, which is able to utilize refractory and allochthonous OM (specialists) as well as more labile, autochthonous OM (generalists). Light availability will also change the relative importance of allochthonous vs. autochthonous OM in flowing water ecosystems and thus affect fungal community structure and function. For example, light facilitates the growth of sessile algae and change the epilithic fungal community with profound consequences for riverine OM cycling ${ }^{188,189}$.

The more that flow velocity decreases and water residence time of an aquatic system increases, the more FPOM and less CPOM will be available as a fungal substrate $^{8}$. In these ecosystems, particularly in isolated lakes, less terrestrial fungi will be introduced and a native fungal community including higher fungi such as Ascomycota may develop. In contrast, rivers downstream receive diverse fungal communities from their tributaries and, therefore, the respective diversity of fungi should be higher. Freshwater fungi, however, might become inactive in estuaries and oceans since increasing salinity may constrain their growth ${ }^{190}$. In a landscape context (Figure 2), the relative proportion of fungi able to produce and degrade OM originating from terrestrial and aquatic ecosystems, the intensity of related mechanisms used (e.g., secretion of reactive oxygen species and specific enzymes), the concentration of generated by-products, and the rate of fungal OM mineralization may substantially change from freshwater ecosystems to the open sea. This will also affect their interactions with prokaryotic microorganisms since bacteria have an increasing advantage over fungi the more OM is available in the dissolved form ${ }^{189}$.

\subsection{Temporal dynamics}

Aside from spatial patterns, there are also temporal constraints linking fungal interactions with seasonal events of $\mathrm{OM}$ availability, e.g. pollen and litter fall, algal blooms (prevalent in temperate to polar regions), and rainy seasons (prevalent in equatorial latitudes). Other more short-term events such as storms and tropical rain showers may increase OM availability in a more pulsed manner (see also the flood pulse concept ${ }^{191}$ ). Consequently, the timing and quantity of OM inputs, both allochthonous and autochthonous, greatly affect the dynamics of aquatic foodwebs and their functioning in a highly dynamic temporal manner ${ }^{11,192}$. For example, pollen rain, when pine trees flower in temperate regions, represents a considerable OM and phosphorus input to lakes ${ }^{193}$. Chytrid fungi are amongst the few organisms able to penetrate through the extracellular wall (exine) of pollen grains ${ }^{22}$, and produce zoospores constituting an effective resource for zooplankton in terms of size, shape and nutritional quality ${ }^{2}$.

For lakes, the PEG model ${ }^{194}$, which describes the seasonal succession of phytoplankton related to physical and biological variables, has been extended by fungal parasitism ${ }^{3,23}$. Fungal parasitism is often caused by chytrids, which can be highly host-specific and lethal, replacing the dominant phytoplankton species with unsusceptible ones. Global warming has the potential to change seasonality of hostparasite interactions, i.e. an accelerated termination of spring diatom blooms and zooplankton peaks ${ }^{23}$.

Fungi can render inedible or indigestible OM to zooplankton forming the "mycoloop" 1,2 , which can seasonally shape planktonic foodwebs, especially when inedible allochthonous OM (e.g., pollen) or autochthonous OM (large algae, toxic cyanobacteria, etc.) dominate ${ }^{2,4}$. To better understand the temporal dynamics of fungal foodweb interactions and their ecological consequences in dependence on 
specific environmental settings, it will be crucial to explore in detail the underlying mechanisms (e.g., the fungal secretome, OM cycling, etc. ${ }^{178}$ ).

\section{Emerging methods, concepts, and perspectives}

Microbiology is a science underpinned by technology, and major discoveries are frequently made, in part, because of the application of novel technological and conceptual approaches. In particular, first and second generation sequencing methods (i.e. Sanger and high throughput sequencing) have played a central role in expanding our understanding of the dimensions of aquatic fungal diversity by accessing DNA sequences from environmental samples. However, since the early diverging fungal lineages do not share a consistent barcode and suffer from severe reference database gaps, a unifying ribosomal barcode is currently being established and refined ${ }^{30,47}$ for third generation long-read sequencers (e.g. PacBio, Oxford Nanopore Technologies). Currently, there is a great need to enhance global isolation efforts since the number of unknown sequences is disproportionally increasing in comparison to the number of described species ${ }^{195}$. Fungal isolates, in particular of currently uncultured fungal groups or those with a few cultured strains, will greatly improve current reference databases (e.g. REF. ${ }^{32,33}$ ). Furthermore, when coupled to single cell microscope inspections, third generation long-read sequencing may help to close the huge reference data gaps for aquatic fungi ${ }^{47,86}$. The increased read length allows to sequencing whole genes (e.g., the complete ribosomal operon) or gene clusters, which facilitate a potential subspecies level of taxonomic resolution. Collective work by fungal researchers will be advisable to shed more light on the "fungal dark matter" by embracing long-read sequencing and their new protocols (e.g. REF. ${ }^{196}$ ), in the same way that second generation sequencing was refined and widely utilised.

Targeted sequencing allows to phylogenetically place and identify formerly unknown ITS barcodes ${ }^{36}$. Recently, the use of the precursor rRNA allowed a first look at the "living" aquatic fungi ${ }^{80}$. The use of spiking of reference DNA may allow a more accurate estimate of the relative abundances that are generated in amplicon sequencing projects ${ }^{197}$. Coupled to the new generation of RNA sequencers (Oxford Nanopore), this may be a powerful approach to primarily focus on the active fungi. Moreover, we have most recently gained the possibility to extract fungal genomes from metagenomes ${ }^{198}$ and single cells ${ }^{46}$, and to apply new high throughput culturing techniques for potentially co-culturing aquatic fungi and bacteria ${ }^{199}$.

Whole genome approaches either from isolated cultures, single cells, or reconstructed from environmental metagenomes are undoubtedly changing the ways in which we view and understand all microbial life. It has been shown that highquality annotated fungal genomes are an important fungal research resource, e.g. for broad-scale comparative gene assessments ${ }^{200}$ and large-scale phylogenomics ${ }^{201}$. These resources can play vital roles in studying aquatic fungi as they enable for a deeper understanding of genome-encoded pathways and enzymatic evolution in un-cultivated lineages, such as basal fungi (e.g. REF. ${ }^{10,202}$ ). This will allow disentangling the multitude of fungal interactions, particularly since early diverging fungal lineages are poorly represented in annotated genome repositories, which the "aquatic fungal dark matter" community should rectify. Finally, ecosystem relevant research on aquatic fungi requires quantifying the fungal contribution, either by model systems (e.g. REF. $^{203}$ ), fatty acids ${ }^{17}$, stable isotopes or labelled FISH ${ }^{177,204-207}$. Thus, it is about time to overcome the insufficient sampling and exploration of natural and artificial aquatic environments to understand the spatial and temporal distribution as well as the dynamics of aquatic fungi. Further, to better understand their physiology, metabolic 
processes, and other behavioural aspects of their life cycle, it is necessary to intensify the isolation and co-cultivation of novel models from both marine and freshwater environments, including host-parasite systems (e.g. REF. ${ }^{33}$ ). We also call for increased efforts to better quantify fungal biomass and activity in the aquatic realm, which requires application of new analytical biochemical methods including news approaches based on stable isotopes and fluorescent markers.

Mycologists and terrestrial microbiologists do not need much convincing about the concepts and importance of aquatic fungi. However, the wider non-fungal aquatic microbial ecology community and scientists of other disciplines (e.g., biological oceanography, limnology, and urban water management) still need some encouragement ${ }^{208}$. This is because of several reasons, some of which have been discussed above, but also because interdisciplinary bridges still need to be built to establish shared and integrated conceptual views. Based on what we know already about the roles of fungi in aquatic ecosystems, their general absence from ecological frameworks (e.g., foodwebs, microbial carbon pump, and greenhouse gas cycling) and computational models represent substantial knowledge gaps and predicative uncertainty.

The importance of fundamental biology to mechanistically underpin ecological understanding of aquatic fungi remains paramount. Likewise, ecological perspectives can prioritise biological studies. However, beyond medical and applied/industrial mycology, there are limited model fungi available relevant for aquatic ecosystems. Community-wide efforts must be made to develop new and meaningful model aquatic fungi including associated experimental capabilities, such as freely accessible annotated genome sequences, live cell imaging and geneknockout protocols (e.g. CRISPR/Cas9 targeted genome editing).

\section{Conclusions}

Aside of a rapid development of molecular approaches, there is an obvious lack of suitable methods to measure fungal activities, biomass and their ecological relevance for overall biogeochemical cycles. Furthermore, our broad conceptual understanding of aquatic fungi has so far been constrained by studies focusing principally on individual ecosystems in a rather isolated manner (e.g., lakes, rivers, estuaries, coastal seas, and open oceans). Aquatic ecosystems, however, are interlinked throughout catchments via the hydrological cycle and are intimately connected to a variety of terrestrial ecosystems through runoff and subsurface water movement. Studies on aquatic fungi have already shown that there is clearly exchange of taxa between ecosystems ${ }^{11,86}$, yet, we have a very limited understanding of the global aquatic mycobiome and its role in global biogeochemical cycles. Future work should consider aquatic fungi with catchment-wide perspectives and within a spatiotemporal context, alongside understanding their roles within individual ecosystems.

Looking ahead, the future and potential of aquatic mycology is bright. What we know already about the biology and ecology of aquatic fungi is evidently less than the 'known unknowns', such as the impact of parasitic fungi in controlling freshwater and marine phytoplankton dynamics and the connections that aquatic fungi make between ecosystems. Perhaps, even more exciting, through the application of the assorted range of developing techniques now available to microbial ecologists, we can address and answer the numerous open questions about aquatic fungi and make many novel discoveries that are yet to be conceived. 


\section{References:}

1. Kagami, M., de Bruin, A., Ibelings, B. W., \& Van Donk, E. Parasitic chytrids: their effects on phytoplankton communities and food-web dynamics.

Hydrobiol., 578, 113-129 (2007).

2. Kagami, M., Miki, T., \& Takimoto, G. Mycoloop: chytrids in aquatic food webs. Front. Microbiol., 5, 166 (2014).

3. Rasconi, S., Niquil, N., \& Sime-Ngando, T. Phytoplankton chytridiomycosis: community structure and infectivity of fungal parasites in aquatic ecosystems. Environ. Microbiol., 14, 2151-2170 (2012).

4. Haraldsson, M. et al. Microbial parasites make cyanobacteria blooms less of a trophic dead end than commonly assumed. ISME J, 12,1008 (2018).

5. Taylor, D. L., \& Sinsabaugh, R. L. The soil fungi: occurrence, phylogeny, and ecology. Soil Microbiol. Ecol. Biochem., 4, 77-109 (2015).

6. Peay, K. G., Kennedy, P. G., \& Talbot, J. M. (2016). Dimensions of biodiversity in the Earth mycobiome. Nat. Rev. Microbiol., 14, 434-447.

7. Shearer, C. A. et al. Fungal biodiversity in aquatic habitats. Biodivers. Conserv., 16, 49-67 (2007).

8. Wurzbacher, C. M., Bärlocher, F., Grossart, H.-P. Fungi in lake ecosystems. Aquat. Microb. Ecol. 59, 125-149 (2010).

9. Richards, T. A. et al. Molecular diversity and distribution of marine fungi across 130 European environmental samples. P. Roy. Soc. B-Biol. Sci., 282, 20152243 (2015).

10. Grossart, H.-P., \& Rojas-Jimenez, K. Aquatic fungi: targeting the forgotten in microbial ecology. Curr. Opin. Microbiol., 31, 140-145 (2016).

11. Taylor, J. D. \& Cunliffe, M. Multi-year assessment of coastal planktonic fungi reveals environmental drivers of diversity and abundance. ISME J, 10, 21182128 (2016).

12. Park, D. On the ecology of heterotrophic micro-organisms in fresh-water. Transact. Brit. Mycol. Soc., 58: 291-299 (1972).

13. Richards, T.A., Jones, M.D.M., Leonard, G. \& Bass, D. Marine fungi: their ecology and molecular diversity. Annu. Rev. Mar. Sci., 4: 495-522 (2012).

14. De Vargas, C. et al. Ocean plankton. Eukaryotic plankton diversity in the sunlit ocean. Science, 348, 1261605 (2015).

15. Debroas, D. et al. Overview of freshwater microbial eukaryotes diversity: a first analysis of publicly available metabarcoding data. FEMS Microbiol. Ecol, 93, fix023 (2017).

16. Krauss G-J, Solé M, Krauss G, Schlosser D, Wesenberg D, \& Bärlocher F. (2011). Fungi in freshwaters: Ecology, physiology and biochemical potential. FEMS Microbiol. Rev., 35: 620-651.

17. Fabian, J., Zlatanovic, S., Mutz, M. \& Premke, K. Fungal-bacterial dynamics and their contribution to terrigenous carbon turnover in relation to organic matter quality. ISME J, 11, 415-25 (2017).

18. Taube, R., Ganzert, L., Grossart, H.-P., Gleixner, G. \& Premke, K. Organic matter quality structures benthic fatty acid patterns and the abundance of fungi and bacteria in temperate lakes. STOTEN, 610: 469-481 (2018).

19. Nikolcheva, L.G. \& Bärlocher, F. Taxon-specific fungal primers reveal unexpectedly high diversity during leaf decomposition in a stream. Mycol. Progr., 3: 41-49 (2004). 
20. Grossart, H.-P., Wurzbacher, C., James, T. Y., \& Kagami, M. Discovery of dark matter fungi in aquatic ecosystems demands a reappraisal of the phylogeny and ecology of zoosporic fungi. Fung. Ecol., 19, 28-38 (2016).

21. Gulis, V., Suberkropp, K., \& Rosemond, A. D. Comparison of fungal activities on wood and leaf litter in unaltered and nutrient-enriched headwater streams. Appl. Environ. Microbiol., 74, 1094-1101 (2008).

22. Wurzbacher, C., Rösel, S., Rychla, A.,\& Grossart, H.-P. Importance of Saprotrophic Freshwater Fungi for Pollen Degradation. PLOS One, 9, e94643 (2014).

23. Frenken, T. et al. Integrating chytrid fungal parasites into plankton ecology: research gaps and needs. Environ. Microbiol., 19, 3802-3822 (2017).

24. Taylor, J. D. \& Cunliffe, M. Coastal bacterioplankton community response to diatom - derived polysaccharide microgels. Environ. Microbiol. Rep., 9, 151157 (2017).

25. Rinke, C. et al. Insights into the phylogeny and coding potential of microbial dark matter. Nature, 499, 431-437 (2013).

26. Woyke, T. \& Rubin, E. M. Searching for new branches on the tree of life. Science, 346, 698-699 (2014).

27. Mukherjee, S. et al. 1,003 reference genomes of bacterial and archaeal isolates expand coverage of the tree of life. Nat. Biotechnol., 35, 676-683 (2017).

28. Mangot, J.-F. et al. Accessing the genomic information of unculturable oceanic picoeukaryotes by combining multiple single cells. Sci. Rep., 7, 41498 (2017).

29. Giner, C. R. et al. Environmental sequencing provides reasonable estimates of the relative abundance of specific picoeukaryotes. Appl. Environ. Microbiol. 82, 4757-4766 (2016).

30. Heeger, F. et al. Long-read DNA metabarcoding of ribosomal rRNA in the analysis of fungi from aquatic environments. Mol. Ecol. Resour. 18: 1500-1514 (2018).

31. Khomich, M., Davey, M. L., Kauserud, H., Rasconi, S., \& Andersen, T. Fungal communities in Scandinavian lakes along a longitudinal gradient. Fungal Ecol., 27, 36-46 (2017).

32. Seto, K., Kagami, M. \& Degawa, Y. Phylogenetic Position of Parasitic Chytrids on Diatoms: Characterization of a Novel Clade in Chytridiomycota. J. Eukaryot. Microbiol. 64: 383-393 (2017).

33. Van den Wyngaert, S., Rojas-Jimenez, K., Seto, K., Kagami, M. \& Grossart, H.P. Diversity and Hidden Host Specificity of Chytrids Infecting Colonial Volvocacean Algae. J. Eukaryot. Microbiol., J Eukaryot Microbiol., 65: 870-88 (2018).

34. Reich, M. \& Labes, A. How to boost marine fungal research: A first step towards a multidisciplinary approach by combining molecular fungal ecology and natural products chemistry. Mar. Genomics, 36, 57-75 (2017).

35. Tedersoo, L. et al. Global diversity and geography of soil fungi. Science, 346, 1256688 (2014).

36. Tedersoo, L., Tooming-Klunderud, A. \& Anslan. S. PacBio metabarcoding of Fungi and other eukaryotes: errors, biases and perspectives. New Phytol., 217, 1370-1385 (2018).

37. Liu, J., Wang, J., Gao, G., Bartlam, M. G. \& Wang, Y. Distribution and diversity of fungi in freshwater sediments on a river catchment scale. Front. Microbiol., 6, 329 (2015).

38. Wang, X., Singh, P., Gao, Z., Zhang, X., Johnson, Z. I. \& Wang, G. Distribution 
and Diversity of Planktonic Fungi in the West Pacific Warm Pool. PLOS One, 9, e101523 (2014).

39. Tisthammer, K.H., Cobian, G.M. \& Ahmend, A.S. Global biogeography of marine fungi is shaped by the environment. Fun. Ecol,. 1: 39-46 (2015).

40. Bahram, M. et al. Structure and function of the global topsoil microbiome. Nature, 560, 233-237 (2018).

41. Duarte, S., Bärlocher, F., Pascoal, C. \& Cassio, F. Biogeography of aquatic hyphomycetes: Current knowledge and future perspectives. Fung. Ecol., 19: 169-181 (2016).

42. Monchy, S., et al. Exploring and quantifying fungal diversity in freshwater lake ecosystems using rDNA cloning/sequencing and SSU tag pyrosequencing.

Environ. Microbiol., 13, 1433-1453 (2011).

43. Picard, K.T. Coastal marine habitats harbor novel early-diverging fungal diversity. Fung. Ecol., 25: 1-13 (2017).

44. Tedersoo L, Bahram M, Puusepp R, Henrik Nilsson, R. \& James, T. Y. Novel soil-inhabiting clades fill gaps in the fungal tree of life. Microbiome, 5, 42 (2017).

45. Tedersoo L. et al. High-level classification of the Fungi and a tool for evolutionary ecological analyses. Fungal Diversity, 90, 135-159 (2018).

46. Ahrendt, S. Ret al. Leveraging single-cell genomics to expand the fungal tree of life. Nature Microbiology. https://doi.org/10.1038/s41564-018-0261-0 [Epub ahead of print] (2018).

47. Wurzbacher, C. et al. Introducing ribosomal tandem repeat barcoding for fungi. Molecular Ecology Resources, https://doi.org/10.1111/1755-0998.12944 [Epub ahead of print] (2018).

48. Jones, E. B. G., Hyde, K. D. \& Pang, K.-L. Freshwater fungi: and fungal-like organisms. Walter de Gruyter GmbH \& Co KG (2014).

49. Comeau, A. M., Vincent, W. F., Bernier, L. \& Lovejoy, C. Novel chytrid lineages dominate fungal sequences in diverse marine and freshwater habitats. Sci. Rep., 6, 30120 (2016).

50. Hassett, B. T., Ducluzeau, A. L., Collins, R. E. \& Gradinger, R. Spatial distribution of aquatic marine fungi across the western Arctic and sub-arctic. Environ. Microbiol., 19, 475-484 (2017).

51. Rojas-Jimenez, K. et al. Early diverging lineages within Cryptomycota and Chytridiomycota dominate the fungal communities in ice-covered lakes of the McMurdo Dry Valleys, Antarctica. Sci Rep., 7, e15348 (2017).

52. Braun, A. Über Chytridium: eine Gattung einzelliger Schmarotzergewächse auf Algen und Infusorien. Gedruckt in der Druckerei der Königl. Akademie der Wissenschaften (1856).

53. Sparrow, F. K. Aguatic phycomycetes. University of Michigan Ann Arbor (1960).

54. Ingold, T. C. An lllustrated Guide to Aquatic Hyphomycetes. Freshw. Biol. Assoc. Sci. Publ., 30: 1-96 (1975).

55. Bärlocher, F. in The ecology of aquatic hyphomycetes (ed. Bärlocher, F.) 1-15 (Spinger, Heidelberg, 1992).

56. Chauvet, E., Cornut, J., Sridhar, K. R., Selosse, M.-A., Bärlocher, F. Beyond the water column: aquatic hyphomycetes outside their preferred habitat. Fungal Ecol., 19, 112-127 (2016).

57. Roth Jr., F. J., Orpurt, P. A. \& Ahearn, D. G. Occurrence and distribution of fungi in a subtropical marine environment. Can. J. Bot., 42, 375-383 (1964). 
58. Raghukumar, C., Damare, S. R. \& Singh, P. A review on deep-sea fungi: occurrence, diversity and adaptations. Bot. Mar., 53, 479-492 (2010).

59. Nagano, Y.\& Nagahama, T. Fungal diversity in deep-sea extreme environments. Fungal Ecol., 5, 463-471 (2012).

60. Zhang, X., Tang, G., Xu, X.-a., Nong, X.-h., Qi, S.-h. Insights into deep-sea sediment fungal communities from the East Indian Ocean using targeted environmental sequencing combined with traditional cultivation. PLOS One, 9, e109118 (2014).

61. Xu, W., Luo, Z.-H., Guo, S. \& Pang, K.-L. Fungal community analysis in the deep-sea sediments of the Pacific Ocean assessed by comparison of ITS, $18 \mathrm{~S}$ and 28S ribosomal DNA regions. Deep Sea Res. Part I Oceanogr. Res. Pap., 109, 51-60 (2016).

62. Edgcomb, V.P., Beaudoin, D., Gast, R., Biddle, J. F., Teske, A. Marine subsurface eukaryotes: the fungal majority. Environ. Microbiol., 13, 172-183 (2011).

63. Ivarsson, M., Bengtson, S. \& Neubeck, A. The igneous oceanic crust-Earth's largest fungal habitat? Fung. Ecol., 20, 249-255 (2016).

64. Orsi, W., Biddle, J. F. \& Edgcomb, V. Deep sequencing of subseafloor eukaryotic rRNA reveals active fungi across marine subsurface provinces. PLOS One, 8, e56335 (2013).

65. López-García, P., Vereshchaka, A. \& Moreira, D. Eukaryotic diversity associated with carbonates and fluid-seawater interface in Lost City hydrothermal field. Environ. Microbiol., 9, 546-554 (2007).

66. Connell, L., Barrett, A., Templeton, A. \& Staudigel, H. Fungal diversity associated with an active deep sea volcano: Vailulu'u Seamount, Samoa. Geomicrobiol. J., 26, 597-605 (2009).

67. Le Calvez, T., Burgaud, G., Mahé, S., Barbier, G. \& Vandenkoornhuyse, P. Fungal diversity in deep-sea hydrothermal ecosystems. Appl. Environ. Microbiol., 75, 6415-6421 (2009).

68. Kutty, S. N. \& Philip, R. Marine yeasts - a review. Yeast, 25, 465-483 (2008).

69. Li, L., Singh, P., Liu, Y., \& Pan, S. \& Wang, G. Diversity and biochemical features of culturable fungi from the coastal waters of Southern China. $A M B$ Express, 4, 60 (2014).

70. Comic, L., Rankovic, B., Novevska, V. \& Ostojic, A. Diversity and dynamics of the fungal community in Lake Ohrid. Aquat. Biol., 9, 169-176 (2010).

71. Gonçalves, V. N., Vaz, A. B. M., Rosa, C. A. \& Rosa, L. H. Diversity and distribution of fungal communities in lakes of Antarctica. FEMS Microbiol. Ecol., 82, 459-471 (2012).

72. Gunde-Cimerman, N. et al. Extremophilic fungi in arctic ice: A relationship between adaptation to low temperature and water activity. Phys. Chem. Earth, 28, 1273-1278 (2003).

73. Hoshino, T. et al. Antifreeze proteins from snow mold fungi. Can. J. Bot., 81, 1175-1181 (2003).

74. Miyamoto, T., Koda, K., Kawaguchi, A. \& Uraki, Y. Ligninolytic Activity at $0^{\circ}$ $\mathrm{C}$ of Fungi on Oak Leaves Under Snow Cover in a Mixed Forest in Japan. Microb. Ecol., 74, 322-331 (2017).

75. Jones, E. B. G. \& Pang, K. L Tropical aquatic fungi. Biodivers. Conserv., 21, 2403-2423 (2012).

76. Zhang. T., Wang N. F., Zhang Y. Q., Liu, H. Y. \& Yu, L. Y. Diversity and Distribution of Aquatic Fungal Communities in the Ny-Ålesund Region, 
Svalbard (High Arctic). Microb. Ecol., 71, 543-554 (2016).

77. Nagano, Y. et al. Fungal diversity in deep-sea sediments associated with asphalt seeps at the Sao Paulo Plateau. Deep Sea Res. Part II Top Stud. Oceanogr., 146, 59-67 (2017).

78. Sohlberg, E. et al. Revealing the unexplored fungal communities in deep groundwater of crystalline bedrock fracture zones in Olkiluoto, Finland. Front. Microbiol., 6, 1-11 (2015).

79. Nawaz, A. et al. bimposed pristine limestone aquifers with marked hydrochemical differences exhibit distinct fungal communities. Front. Microbiol., 7, 1-11 (2016).

80. Nawaz, A. et al. First insights into the living groundwater mycobiome of the terrestrial biogeosphere. Water Res., 145, 50-61 (2018).

81. Brad, T., Braster, M., van Breukelen, B. M., van Straalen, N. M.\& Rölinget, W. F. M. Eukaryotic diversity in an anaerobic aquifer polluted with landfill leachate. Appl. Environ. Microbiol., 74, 3959-3968 (2008).

82. Fasanella, C. C. et al. The selection exerted by oil contamination on mangrove fungal communities. Water Air Soil Pollut., 223, 4233-4243 (2012).

83. Simister, R. L. et al. Degradation of oil by fungi isolated from Gulf of Mexico beaches. Mar. Pollut. Bull., 100, 327-333 (2015).

84. Lepere, C., Boucher, D., Jardillier, L., Domaizon, I. \& Debroas, D. Succession and regulation factors of small eukaryote community composition in a lacustrine ecosystem (Lake Pavin). Appl. Environ. Microbiol., 72, 2971-2981 (2006).

85. Jobard, M., Rasconi, S., Solinhac, L., Cauchie, H. M., Sime-Ngando, T. Molecular and morphological diversity of fungi and the associated functions in three European nearby lakes. Environ. Microbiol., 14, 2480-2494 (2012).

86. Ishida, S., Nozaki, D., Grossart, H.-P. \& Kagami, M. Novel basal, fungal lineages from freshwater phytoplankton and lake samples. Environ. Microbiol. Rep., 7, 435-441 (2015).

87. Panzer, K. et al. Identification of habitat-specific biomes of aquatic fungal communities using a comprehensive nearly full-length $18 \mathrm{~S}$ rRNA dataset enriched with contextual data. PLOS One, 10, 1-20 (2015).

88. Wurzbacher, C. et al. High habitat-specificity in fungal communities in oligomesotrophic, temperate Lake Stechlin (North-East Germany). MycoKeys, 16, 17-44 (2016).

89. Lazarus, K. L. \& James, T. Y. Surveying the biodiversity of the Cryptomycota using a targeted PCR approach. Fungal Ecol., 14, 62-70 (2015).

90. Jeffries, T. C. et al. Partitioning of fungal assemblages across different marine habitats. Environ. Microbiol. Rep., 8, 235-238 (2016).

91. Picard, K. T. Coastal marine habitats harbor novel early-diverging fungal diversity. Fungal Ecol., 25, 1-13 (2017).

92. Wang, Y. et al. Distinct seasonality of chytrid-dominated benthic fungal communities in the neritic oceans (Bohai Sea and North Yellow Sea). Fungal Ecol., 30, 55-66 (2017).

93. Naff, C. S., Darcy, J. L. \& Schmidt, S. K. Phylogeny and biogeography of an uncultured clade of snow chytrids. Environ. Microbiol., 15, 2672-2680 (2013).

94. Hassett, B. T. \& Gradinger, R. Chytrids dominate arctic marine fungal communities. Environ. Microbiol., 18, 2001-2009 (2016).

95. Rämä, T., Hassett, B. T. \& Bubnova, E. Arctic marine fungi: from filaments and flagella to operational taxonomic units and beyond. Bot. Mar., 60, 433-452 
(2017).

96. Gilbert, J. A., \& Stephens, B. Microbiology of the built environment. Nat. Rev. Microbiol., 16, 661-670 (2018)..

97. Babič, M. N. , Zalar P, Ženko B, Džeroski, S. \& Gunde-Cimerman, N. Yeasts and yeast-like fungi in tap water and groundwater, and their transmission to household appliances. Fungal Ecol., 20, 30-39 (2016).

98. Hervé, V., Leroy, B., Pires, A. D. S. \& Lopez, P. J. Aquatic urban ecology at the scale of a capital: community structure and interactions in street gutters. ISME $J$, 12, 253-266 (2017).

99. Becker, J. G. \& Shaw, C. G. Fungi in domestic sewage-treatment plants. Appl. Microbiol., 3, 173-180 (1955).

100. Evans, T. N. \& Seviour, R. J. Estimating biodiversity of fungi in activated sludge communities using culture-independent methods. Microb. Ecol., 63, 773786 (2012)

101. Chouari, R. et al. Eukaryotic molecular diversity at different steps of the wastewater treatment plant process reveals more phylogenetic novel lineages. World J. Microbiol. Biotechnol., 33, 44 (2017).

102. Hirakata, Y., Hatamoto, M., Oshiki, M., Araki, N. \& Yamaguchi, T. in Frontiers International Conference on Wastewater Treatment and Modelling (ed. Mannina, G.) 218-224 (Springer, Cham, 2017).

103. Miyaoka, Y., Hatamoto, M., Yamaguchi, T. \& Syutsubo, K. Eukaryotic community shift in response to organic loading rate of an aerobic trickling filter (down-flow hanging sponge reactor) treating domestic sewage. Microb. Ecol., 73, 801-814 (2017).

104. Maza-Márquez, P. et al. Community structure, population dynamics and diversity of fungi in a full-scale membrane bioreactor (MBR) for urban wastewater treatment. Water Res., 105, 507-519 (2016).

105. Hofmann, U. et al. Evaluation of the applicability of the aquatic ascomycete Phoma sp. UHH $5-1$ - 03 for the removal of pharmaceutically active compounds from municipal wastewaters using membrane bioreactors. Engin Life Sci., 18, 510-519 (2018).

106. Seppälä, S., Knop, D., Solomon, K. V. \& O’Malley, M. A. The importance of sourcing enzymes from non-conventional fungi for metabolic engineering \& biomass breakdown. Metab. Engin., 44, 45-59 (2017).

107. Zhou, W. et al. Novel fungal pelletization-assisted technology for algae harvesting and wastewater treatment. Appl. Biochem. Biotechnol., 167, 214-228 (2012).

108. Letcher, P. M. et al. Characterization of Amoeboaphelidium protococcarum, an Algal Parasite New to the Cryptomycota Isolated from an Outdoor Algal Pond Used for the Production of Biofuel. PLOS One, 8, e56232 (2013).

109. Beyter, D. et al. Diversity, Productivity and Stability of an Industrial Microbial Ecosystem. Appl. Environ. Microbiol. 82, 2494-2505 (2016).

110. Shurin, J. B. et al. Industrial-strength ecology: trade-offs and opportunities in algal biofuel production. Ecol. Lett. 16, 1393-1404 (2013).

111. Carney, L. T. \& Lane, T. W. Parasites in algae mass culture. Front. Microbiol., 5, 278 (2014).

112. Letcher, P. M. et al Morphological, molecular, and ultrastructural characterization of Rozella rhizoclosmatii, a new species in Cryptomycota. Fungal Biol., 121, 1-10 (2017). 
113. Lightner, D. V. \& Redman, R. M. (1998) Shrimp diseases and current diagnostic methods. Aquaculture, 164, 201-220.

114. Nylund, S., Nylund, A., Watanabe, K., Arnesen, C. E. \& Karlsbakk, E. Paranucleospora theridion n. gen., n. sp.(Microsporidia, Enterocytozoonidae) with a life cycle in the salmon louse (Lepeophtheirus salmonis, Copepoda) and Atlantic salmon (Salmo salar). J. Euk. Microbiol., 57, 95-114 (2010).

115. Bartelme, R. P., Oyserman, B. O., Blom, J.E., Sepulveda-Villet, O. J. \& Newton, R. J. Stripping Away the Soil: Plant Growth Promoting Microbiology Opportunities in Aquaponics. Front. Microb., 9, 8 (2018).

116. Nobu, M. K. et al. Microbial dark matter ecogenomics reveals complex synergistic networks in a methanogenic bioreactor. ISME J, 9, 1710-22 (2015).

117. Zhdanova, N. N., Zakharchenko, V. A., Vember, V. V. \& Nakonechnaya, L.T. Fungi from Chernobyl: mycobiota of the inner regions of the containment structures of the damaged nuclear reactor. Mycol. Res., 104, 1421-1426 (2000).

118. Neu, L. et al. Ugly ducklings-the dark side of plastic materials in contact with potable water. npj Biofilms and Microbiomes, 4, 7 (2018).

119. Kettner MT, Rojas-Jimenez K, Oberbeckmann S, Labrenz \& M., Grossart, H.-P. Microplastics alter composition of fungal communities in aquatic ecosystems. Environ. Microbiol., 19, 4447-4459 (2017).

120. Arias-Andres, M., Klümper, U., Rojas-Jimenez, K. \& Grossart, H.-P. Microplastic pollution increases gene exchange in aquatic ecosystems. Environ. Pollut., 237, 253-261 (2018).

121. Herrero, N., Sánchez Márquez, S. \& Zabalgogeazcoa, I. (2009). Mycoviruses are common among different species of endophytic fungi of grasses. Arch. Virol., 154, 327-330.

122. Nerva, L. et al. Multiple approaches for the detection and characterization of viral and plasmid symbionts from a collection of marine fungi. Virus Res., 219, 22-38 (2016).

123. Gulis, V. \& Suberkropp, K. Interactions between stream fungi and bacteria associated with decomposing leaf litter at different levels of nutrient availability. Aquat. Microb. Ecol., 30, 149-157 (2003).

124. Park, S.T., Collingwood, A.M., St-Hilaire, S. \& Sheridan, P.P. Inhibition of Batrachochytrium dendrobatidis Caused by Bacteria Isolated from the Skin of Boreal Toads, Anaxyrus (Bufo) boreas boreas, from Grand Teton National Park, Wyoming, USA. Microbiology Insights, 7, 1-8 (2014).

125. Mille-Lindblom, C. \& Tranvik, L.J. Antagonism between Bacteria and Fungi on Decomposing Aquatic Plant Litter. Microb. Ecol., 45, 173-182 (2003).

126. Schorn, S. \& Cypionka, H. A Crispy Diet: Grazers of Achromatium oxaliferum in Lake Stechlin Sediments. Microb. Ecol., 76, 584-587 (2018).

127. Bengtsson, G. Interactions between fungi, bacteria and beech leaves in a stream microcosm. Oecologia, 89, 542-549 (1992).

128. Senga, M., Yabe, S., Nakamura, T. \& Kagami, M. Influence of parasitic chytrids on the quantity and quality of algal dissolved organic matter (AOM). Water Res., doi: 10.1016/j.watres.2018.08.037. [Epub ahead of print] (2018).

129. Deveau, A. et al. Bacterial-fungal interactions: ecology, mechanisms and challenges. FEMS Microbiol. Rev., 42, 335-352 (2018).

130. Corsaro, D. et al. New insights from molecular phylogenetics of amoebophagous fungi (Zoopagomycota, Zoopagales). Parasitol. Res., 117, 157 167 (2018). 
131. Canter-Lund, H. \& Lund, J.W.G. Freshwater algae: their microscopic world explored. Biopress Ltd, Bristol, England (1995).

132. Lee, S.S., Ha, J.K. \& Cheng, K.J. Relative Contributions of Bacteria, Protozoa, and Fungi to In Vitro Degradation of Orchard Grass Cell Walls and Their Interactions. Appl. Environ. Microbiol., 66, 3807-3813 (2000).

133. Lueders, T., Wagner, B., Claus, P. \& Friedrich, M.W. Stable isotope probing of rRNA and DNA reveals a dynamic methylotroph community and trophic interactions with fungi and protozoa in oxic rice field soil. Environmental Microbiology, 6, 60-72 (2004).

134. Song, C. et al. Molecular and chemical dialogues in bacteria-protozoa interactions. Scientific Reports, 5, 12837 (2015).

135. Gleason, F. H., Marano, A. V., Lilje, O. \& Lange, L. What has happened to the "aquatic phycomycetes" (sensu Sparrow)? Part I: A brief historical perspective. Fungal Biol. Rev., 32, 26-33 (2018).

136. Raghukumar, C. in Seaweed taxonomic identification, aquaculture, resource environment, fouling and disease (ed. Tewari, A.) 366-385 (Central Salt \& Mar. Chem. Res. Inst, 2006).

137. Canter, H. M. \& Lund, J. W. G. The parasitism of planktonic desmids by fungi. Österreichische botanische Zeitschrift, 116, 351-377 (1969).

138. Hanic, L. Sekimoto, A., S. \& Bates, S. S. Oomycete and chytrid infections of the marine diatom Pseudo-nitzschia pungens (Bacillariophyceae) from Prince Edward Island, Canada. Botany, 87, 1096-1105 (2009).

139. Czeczuga, B., Godlewska, A. \& Kozłowska, M. Zoosporic fungi growing on the carapaces of dead zooplankton organisms. Limnologica - Ecol. Man. Inland Wat., 30, 37-43 (2000).

140. Willsey, T., Chatterton, S. \& Cárcamo, H. Interactions of Root-Feeding Insects with Fungal and Oomycete Plant Pathogens. Frontiers in Plant Science, 8, 1764 (2017).

141. Picard, K. T., Letcher, P. M., \& Powell, M. J. Evidence for a facultative mutualist nutritional relationship between the green coccoid alga Bracteacoccus sp.(Chlorophyceae) and the zoosporic fungus Rhizidium phycophilum (Chytridiomycota). Fungal Biol., 117, 319-328 (2013).

142. Allen, J.L. et al. Allelopathic inhibition of primary producer growth and photosynthesis by aquatic fungi. Fungal Ecology, 29, 133-138 (2017).

143. Hawksworth, D.L. in: Aquatic Mycology across the Millennium (eds. Hyde, K.D., Ho, W. \& Pointing, S.B.). Fungal Div., 5, $1-7$ (2000).

144. Hom, E. F. Y. \& Murray, A. W. Niche engineering demonstrates a latent capacity for fungal-algal mutualism. Science, 345, 94 (2014).

145. Gomes, F.C., Safar, S.V., Marques, A.R., Medeiros, A.O., Santos, A.R.O., Carvalho, C., et al. The diversity and extracellular enzymatic activities of yeasts isolated from water tanks of Vriesea minarum, an endangered bromeliad species in Brazil, and the description of Occultifur brasiliensis fa, sp. nov. Antonie van Leeuwenhoek, 107: 597-611(2015).

146. Marins, J. F. D. \& Carrenho, R. Arbuscular mycorrhizal fungi and dark septate fungi in plants associated with aquatic environments. Acta Botanica Brasilica, 31:295-308 (2017).

147. Suryanarayanan, T. S., Kumaresan, V. \& Johnson, J. A. Foliar fungal endophytes from two species of the mangrove Rhizophora. Can J. Microbiol., 44, 1003-1006 (1998). 
148. Viterbo, A. \& Horwitz, B. in Cellular and Molecular Biology of Filamentous Fungi (ed. Borkovich, K. \& Ebbole, D.) 676-693 (ASM Press, Washington, 2010).

149. Letcher, P. M. Morphology, Ultrastructure, and Molecular Phylogeny of Rozella multimorpha, a New Species in Cryptomycota. J. Eukaryot. Microbiol., 65,180190 (2018).

150. Howe, M. J. \& Suberkropp, K. Effects of Mycoparasitism on an Aquatic Hyphomycete Growing on Leaf Litter. Mycologia, 85:898-901 (1993).

151. Skerratt, L. F. et al. Spread of Chytridiomycosis Has Caused the Rapid Global Decline and Extinction of Frogs. EcoHealth, 4, 125 (2007).

152. Ebert, D. Ecology, Epidemiology, and Evolution of Parasitism in Daphnia (ed. Ebert, D.) chapter 3 (National Center for Biotechnology Information (US), Bethesda (MD), 2005).

153. Johnson, P. T. J., Ives, A. R., Lathrop, R. C. \& Carpenter, S. R. Long-term disease dynamics in lakes: causes and consequences of chytrid infections in Daphnia populations. Ecology, 90, 132-144 (2009).

154. Yarden, O. Fungal association with sessile marine invertebrates. Front Microbiol., 5: 228-228 (2014).

155. Whisler, H. C., Zebold, S. L. \& Shemanchuk, J. A. Life history of Coelomomyces psorophorae. Proc. Nat. Acd. Sci., 72, 693-696 (1975).

156. Kagami, M., von Elert, E., Ibelings, B.W., de Bruin, A. \& Van Donk, E. The parasitic chytrid, Zygorhizidium, facilitates the growth of the cladoceran zooplankter, Daphnia, in cultures of the inedible alga, Asterionella. P. Roy. Soc. B-Biol. Sci., 274, 1561-1566 (2007).

157. Schmeller, D. S. et al. Microscopic Aquatic Predators Strongly Affect Infection Dynamics of a Globally Emerged Pathogen. Curr. Biol., 24, 176-180 (2014).

158. McCreadie, J. W. Adler, P. H. \& Beard, C. E. Ecology of Symbiotes of Larval Black Flies (Diptera: Simuliidae): Distribution, Diversity, and Scale. Environ. Entomol., 40, 289-302 (2011).

159. Lichtwardt, R.W. The Trichomycetes: fungal associates of arthropods. New York: Springer-Verlag. 343 p (1986).

160. Wijayawardene, N. N. et al. Notes for genera: basal clades of Fungi (including Aphelidiomycota, Basidiobolomycota, Blastocladiomycota, Calcarisporiellomycota, Caulochytriomycota, Chytridiomycota, Entomophthoromycota, Glomeromycota, Kickxellomycota, Monoblepharomycota, Mortierellomycota, Mucoromycota, Neocallimastigomycota, Olpidiomycota, Rozellomycota and Zoopagomycota). Fungal Diversity, 92, 43-129 (2018).

161. Paterson, R. A. Observations on two species of Rhizophydium from Northern Michigan. Trans. Br. Mycol. Soc., 46, 530-536 (1963).

162. Chamberlain, S. A., Bronstein, J. L. \& Rudgers, J. A. How context dependent are species interactions? Ecol. Lett., 17, 881-890 (2014).

163. Thompson, J. N. The Geographic Mosaic of Coevolution. University of Chicago Press, Chicago. 442 pp (2005).

164. Anderson, J.L. \& Shearer, C.A. Population Genetics of the Aquatic Fungus Tetracladium marchalianum over Space and Time. PLOS One, 6, e15908 (2011).

165. Gleason, F. H. et al. Ecological functions of zoosporic hyperparasites. Front. Microbiol. 5, 244 (2014). 
166. Parratt, S. R. \& Laine, A.-L. The role of hyperparasitism in microbial pathogen ecology and evolution. ISME J, 10, 1815-1822 (2016).

167. Lefèvre, E., Letcher, P.M. \& Powell, M.J. Temporal variation of the small eukaryotic community in two freshwater lakes: emphasis on zoosporic fungi. Aquat. Microb. Ecol., 67, 91-105 (2012).

168. Lepelletier, F. et al. Dinomyces arenysensis gen. et sp. nov. (Rhizophydiales, Dinomycetaceae fam. nov.), a Chytrid Infecting Marine Dinoflagellates. Protist, 165, 230-244 (2014).

169. Gutiérrez, D. et al. Incidence of Staphylococcus aureus and analysis of associated bacterial communities on food industry surfaces. Appl. Environ. Microbiol., 78, 8547-8554 (2012).

170. Gleason, F. H., Kagami, M., Lefèvre, E. \& Sime-Ngando, T. The ecology of chytrids in aquatic ecosystems: roles in food web dynamics. Fungal Biol. Rev., 22, 17-25 (2008).

171. Sime-Ngando, T. Phytoplankton chytridiomycosis: fungal parasites of phytoplankton and their imprints on the food web dynamics. Front. Microbiol., 12, 361 (2012).

172. Gachon, C. M. M., Sime-Ngando, T., Strittmatter, M., Chambouvet, A. \& Kim, G.H. Algal diseases: spotlight on a black box. Trends Plant Sci., 15, 633-640 (2010).

173. Harms, H., Schlosser, D. \& Wick, L. Y. Untapped potential: exploiting fungi in bioremediation of hazardous chemicals. Nat. Rev. Microbiol., 9, 177-192 (2011).

174. Suberkropp, K., \& Klug, M. J. The maceration of deciduous leaf litter by aquatic hyphomycetes. Can. J. Botany, 58, 1025-1031 (1980).

175. Crowther, T. W. \& Grossart, H.-P. in Trophic Ecology: Bottom-Up and TopDown Interactions Across Aquatic and Terrestrial Systems (eds. Hanley, T.C. \& La Pierre, K.J.) 260-287 (Cambridge University Press. Cambridge, 2015).

176. Grami, B., Rasconi, S., Niquil, N., Jobard, M., Saint-Béat, B., \& Sime-Ngando, $\mathrm{T}$. Functional effects of parasites on food web properties during the spring diatom bloom in Lake Pavin: a linear inverse modeling analysis. PLOS One, 6, e23273 (2011).

177. Bochdansky, A. B., Clouse, M. A. \& Herndl, G. J. Eukaryotic microbes, principally fungi and labyrinthulomycetes, dominate biomass on bathypelagic marine snow. ISMEJ, 11, 362-373 (2017).

178. Cunliffe, M., Hollingsworth, A., Bain, C., \& Taylor, J. D. Algal polysaccharide utilisation by saprotrophic planktonic marine fungi. Fungal Ecol., 30, 135-138 (2017).

179. Scholz, B., Küpper, F. C., Vyverman, W. \& Karsten, U. Eukaryotic pathogens (Chytridiomycota and Oomycota) infecting marine microphytobenthic diatomsa methodological comparison. J. Phycol., 50, 1009-1019 (2014).

180. Attermeyer, K., Premke, K., Hornick, T., Hilt, S. \& Grossart, H.-P. Ecosystemlevel studies of terrestrial carbon reveal contrasting bacterial metabolism in different aquatic habitats. Ecology, 94, 2754-2766 (2013).

181. Brouard, O. et al. Understorey environments influence functional diversity in tank-bromeliad ecosystems. Freshwater Biol., 57: 815-823 (2012).

182. Dethier, M. N. Degrading detritus: Changes in food quality of aging kelp tissue varies with species. J. Exp. Mar. Biol. Ecol., 460, 72-79.

183. Raja, H. A., Shearer, C. A.\& Tsui, C. K. Freshwater Fungi. In: eLS. John Wiley \& Sons Ltd, Chichester), doi: 10.1002/9780470015902.a0027210 (2018). 
184. Vannote, R. L., Minshall, G. W., Cummins, K. W., Sedell, J. R. \& Cushing, C. E. The River Continuum Concept. Can. J. Fish. Aquat. Sci., 37, 130-137 (1980).

185. Biswas, S. \& Wagner, H. Landscape contrast: a solution to hidden assumptions in the metacommunity concept?" Landscape Ecol., 27, 621-631 (2012).

186. Battin, T. J., Wille, A., Psenner, R. \& Richter, A. Large-scale environmental controls on microbial biofilms in high-alpine streams. Biogeosc., 1, 159-171 (2004).

187. Ortiz-Álvarez, R., Triadó-Margarit, X., Camarero, L., Casamayor, E. O., \& Catalan, J. High planktonic diversity in mountain lakes contains similar contributions of autotrophic, heterotrophic and parasitic eukaryotic life forms. Sci. Rep., 8, 4457 (2018).

188. Miura, A., \& Urabe, J. Changes in epilithic fungal communities under different light conditions in a river: A field experimental study. Limnol. Oceanogr., 62, 579-591 (2017).

189. Fabian, J. et al. Environmental Control on Microbial Turnover of Leaf Carbon in Streams - Ecological Function of Phototrophic-Heterotrophic Interactions. Front. Microbiol., 9, 1044 (2018).

190. Mohamed, D.J. \& Martiny, J. B. H. Patterns of fungal diversity and composition along a salinity gradient. ISME J, 5, 379-388 (2011).

191. Junk, W. J., Bayley, P. B. \& Sparks, R. E. in Proceedings of the International Large River Symposium (ed. D.P. Dodge) 110-127 (Can. Spec. Publ. Fish. Aquat. Sci., 106, 1989).

192. Cole, J. J. et al. Differential support of lake food webs by three types of terrestrial organic carbon. Ecol. Lett., 9, 558-568 (2006).

193. Rösel, S., Rychla, A., Wurzbacher, C. \& Grossart, H.-P. Effects of pollen leaching and microbial degradation on organic carbon and nutrient availability in lake water. Aquat. Sci., 74, 87-99 (2012).

194. Sommer, U. et al. Beyond the Plankton Ecology Group (PEG) Model: Mechanisms Driving Plankton Succession. Ann. Rev. Ecol., Evol. Sys., 43: 429448 (2012).

195. Truong, C. et al. How to know the fungi: combining field inventories and DNAbarcoding to document fungal diversity. New Phytologist, 214: 913-919 (2017).

196. Calus, S. T., Ijaz, U. Z. \& Pinto, A. J. NanoAmpli-Seq: A workflow for amplicon sequencing from mixed microbial communities on the nanopore sequencing platform. GigaScience, giy140 (2018).

197. Tkacz, A., Hortala, M. \& Poole, P. S. Absolute quantitation of microbiota abundance in environmental samples. Microbiome, 6, 110 (2018).

198. West, P. T., Probst, A.,, Grigoriev, I. V., Thomas, B. C. \& Banfield, J. F. Genome-reconstruction for eukaryotes from complex natural microbial communities. Genome Res., 28, 569-580 (2018).

199. Garcia, S. L., Buck, M., Hamilton, J. J., Wurzbacher, C., Grossart, H.-P., McMahon, K. D., \& Eiler, A. Model Communities Hint at Promiscuous Metabolic Linkages between Ubiquitous Free-Living Freshwater Bacteria. mSphere, 3, e00202-18 (2018).

200. Mondo, S. J. et al. Widespread adenine N6-methylation of active genes in fungi. Nat. Genet., 49, 964-968 (2017).

201. Spatafora, J. W. et al. A phylum-level phylogenetic classification of zygomycete fungi based on genome-scale data. Mycologia, 108, 1028-1046 (2016). 
202. Haag, K. L. et al. Evolution of a morphological novelty occurred before genome compaction in a lineage of extreme parasites. Proc. Natl. Acad. Sci., 111, 15480-15485 (2014).

203. Agha R, Gross A, Gerphagnon M, Rohrlack, T. \& Wolinska, J. Fitness and ecophysiological response of a chytrid fungal parasite infecting planktonic cyanobacteria to thermal and host genotype variation. Parasitol., 145, 12791286 (2018).

204. Orsi, W. D. Ecology and evolution of seafloor and subseafloor microbial communities. Nat. Rev. Microbiol. 16, 671-683 (2018).

205. Wankel, S. D. et al. Evidence for fungal and chemodenitrification based $\mathrm{N}_{2} \mathrm{O}$ flux from nitrogen impacted coastal sediments. Nature Com., 8, 15595 (2017).

206. Drake, H. et al. Anaerobic consortia of fungi and sulfate reducing bacteria in deep granite fractures. Nature Com. 8, 55 (2017).

207. Jobard, M., Rasconi, S. \& Sime-Ngando, T. Fluorescence in situ hybridization of uncultured zoosporic fungi: Testing with clone-FISH and application to freshwater samples using CARD-FISH. J. Microbiol. Methods, 83, 236-243 (2010).

208. Gasol, J. P. \& Kirchman, D. L. Microbial Ecology of the Oceans, $3^{\text {rd }}$ Edition, Wiley-Blackwell, 528 pages, ISBN: 978-1-119-10718-7 (2018).

Acknowledgements

The authors thank Jose Salazar for graphical design. H.P.G. was supported by DFG grants GR1540/23-1 and GR1540/ 30-1.

Author contributions

H.P.G. researched data for the article. H.P.G., S.V.d.W., M.K., C.W., M.C., K.R-J. wrote the article. K.R-J. and H.P.G designed the figures, and S.V.dp.W. provided the microscopic images. All authors contributed substantially to discussion of the content and reviewed and edited the manuscript before submission. We thank 3 anonymous reviewers for their valuable comments and suggestions.

Competing interests

The authors declare no competing interests. 
Table 1. Predominant fungi in natural and artificial aquatic habitats determined by cultivation and cultivation-independent methods. References are given in the supplemental (TABLE S1).

\begin{tabular}{|c|c|c|}
\hline $\begin{array}{l}\text { Aquatic habitats } \\
\text { for fungi }\end{array}$ & $\begin{array}{l}\text { Dominant } \\
\text { groups }\end{array}$ & Common genera \\
\hline $\begin{array}{l}\text { rivers, streams and } \\
\text { ponds }\end{array}$ & Hyphomycetes & Tetracladium, Cercospora, Mycocentrospora, Ophioceras \\
\hline deep-sea & $\begin{array}{l}\text { Filamentous } \\
\text { fungi and yeasts }\end{array}$ & $\begin{array}{l}\text { Aspergillus, } \\
\text { Penicillium, Cladosporium, Cadophora, Fusarium, Mycosphaerella, } \\
\text { Alternaria, Aureobasidium, Cryptococcus, Rhodotorula, } \\
\text { Rhodosporidium, Candida, Pichia, Malassezia, Pleurotus, } \\
\text { Ganoderma }\end{array}$ \\
\hline subsea floor & $\begin{array}{l}\text { Yeasts and } \\
\text { filamentous } \\
\text { fungi }\end{array}$ & $\begin{array}{l}\text { Cryptococcus, Trichosporon, Malassezia, Candida, Rhodotorula, } \\
\text { Rhodosporidium, Exophiala }\end{array}$ \\
\hline hydrothermal vents & $\begin{array}{l}\text { Yeasts, } \\
\text { Chytridiomycota }\end{array}$ & Aureobasidium, Malassezia, Rhodotorula, Exophiala \\
\hline $\begin{array}{l}\text { coastal and oceanic } \\
\text { environments }\end{array}$ & $\begin{array}{l}\text { Ascomycota, } \\
\text { Chytridiomycota, } \\
\text { Basidiomycota, } \\
\text { Rozellomycota }\end{array}$ & $\begin{array}{l}\text { Candida, Cryptococcus, Debaryomyces and Rhodotorula, } \\
\text { Rhodosporidium, Malassezia, Trichosporon, Phaeosphaeria, } \\
\text { Aspergillus, Cladosporium, Rhyzophydium, Chytridium, } \\
\text { Lobulomyces, Spizellomyces }\end{array}$ \\
\hline lakes & $\begin{array}{l}\text { Chytridiomycota, } \\
\text { Ascomycota, } \\
\text { Basidiomycota, } \\
\text { Rozellomycota }\end{array}$ & $\begin{array}{l}\text { Rhizophydium, Lobulomyces, Zygorhizidium, Chytriomyces, } \\
\text { Kappamyces, Chytridium, Rhizophyctis, Rhodotorula, } \\
\text { Rhodosporidium, Sporobolomyces, Cryptococcus, Geotrichum, } \\
\text { Debaryomyces, Saccharomyces, Candida, Pichia, Cordyceps, } \\
\text { Simplicillium, Trichispora, Agaricus, LKM11, LKM15, Rozella }\end{array}$ \\
\hline ice and snow & $\begin{array}{l}\text { Ascomycota, } \\
\text { Basidiomycota, } \\
\text { Chytridiomycota }\end{array}$ & $\begin{array}{l}\text { Cladosporium, Aureobasidium, Penicillium, Coccomyces, Xylaria, } \\
\text { Coprinus, Typhula, Mycena, Rhizophydiales }\end{array}$ \\
\hline aquifers & $\begin{array}{l}\text { Ascomycota, } \\
\text { Basidiomycota, } \\
\text { Zygomycota }\end{array}$ & $\begin{array}{l}\text { Nectria, Fusarium, Penicillium, Sporobolomyces, Rhodotorula, } \\
\text { Cryptococcus, Malassezia, Mortierella }\end{array}$ \\
\hline polar systems & $\begin{array}{l}\text { Chytridiomycota, } \\
\text { Rozellomycota, } \\
\text { Dikarya }\end{array}$ & $\begin{array}{l}\text { Rhizophydium, Podochytrium, Rhizoclosmatium, Chytriomyces, } \\
\text { Cladochytrium, Cyclopsomyces, Lobulomyces, Mesochytrium, } \\
\text { Polychytrium, LKM11, Glaciozyma, Mrakia, Cadophora, } \\
\text { Penicillium, Rhodotorula, Epicoccum, Cladosporium, } \\
\text { Sporobolomyces, Kluyveromyces, Aureobasidium, Candida, } \\
\text { Basidiobolus }\end{array}$ \\
\hline $\begin{array}{l}\text { waste water } \\
\text { treatment plants } \\
\text { and sludge } \\
\text { digesters }\end{array}$ & $\begin{array}{l}\text { Rozellomycota, } \\
\text { Ascomycota, } \\
\text { Basidiomycota }\end{array}$ & $\begin{array}{l}\text { LKM11, Claviceps, Aureobasidium, Candida, Geotrichum, } \\
\text { Penicillium }\end{array}$ \\
\hline $\begin{array}{l}\text { street gutters and } \\
\text { street pipes }\end{array}$ & $\begin{array}{l}\text { Chytridiomycota, } \\
\text { yeasts }\end{array}$ & Chaetothyriales, Cryptococcus \\
\hline $\begin{array}{l}\text { tap water and ice } \\
\text { cubes }\end{array}$ & $\begin{array}{l}\text { Yeasts, } \\
\text { filamentous } \\
\text { fungi }\end{array}$ & $\begin{array}{l}\text { Aureobasidium, Exophiala, Candida, Cryptococcus, Penicillium, } \\
\text { Rhodotorula, Aspergillus }\end{array}$ \\
\hline swimming pools & Ascomycota & $\begin{array}{l}\text { Candida, Pichia, Saccharomyces, Rhodosporidium, Rhodotorula, } \\
\text { Aspergillus, Trichophyton }\end{array}$ \\
\hline nuclear reactors & $\begin{array}{l}\text { Ascomycota, } \\
\text { Zygomycota }\end{array}$ & $\begin{array}{l}\text { Cladosporium, Penicillium, Alternaria, Aureobasidium, Aspergillus, } \\
\text { Acremonium, Phialophora, Mucor, Chaetomium }\end{array}$ \\
\hline $\begin{array}{l}\text { International Space } \\
\text { Station }\end{array}$ & Ascomycota & $\begin{array}{l}\text { Penicillium, Aspergillus, Cladosporium, Pezicula, Malassezia, } \\
\text { Inonotus }\end{array}$ \\
\hline
\end{tabular}


Table 2. Fungal occurrence in a landscape concept (Earth's Mycobiome), whereby the main environmental drivers i.e. connectivity between aquatic ecosystems, vectors for fungal dispersal and temporal dynamics act at different spatial scales. Human interferences also changes with spatial scale, but today reaches from the micro- up to the global scale.

\begin{tabular}{|c|c|c|c|c|c|}
\hline Scale: & global & regional & local & microscale & molecular \\
\hline \multirow[t]{2}{*}{$\begin{array}{l}\text { Spatial } \\
\text { Connectivity }\end{array}$} & $\begin{array}{l}\text { Climatic zones, } \\
\text { Rivers-oceans } \\
\text { (water currents, } \\
\text { winds, etc.) }\end{array}$ & $\begin{array}{l}\text { "River continuum } \\
\text { concept", } \\
\text { (water currents, } \\
\text { winds, etc.) }\end{array}$ & $\begin{array}{l}\text { Aquatic- } \\
\text { terrestrial } \\
\text { coupling, } \\
\text { Deep sea vents, } \\
\text { Eddies, etc. }\end{array}$ & $\begin{array}{l}\text { Organismic } \\
\text { interactions, } \\
\text { Metabolome } \\
\text { exchange }\end{array}$ & $\begin{array}{c}\text { Gene exchange, } \\
\text { DOM/POM } \\
\text { degradation + } \\
\text { production }\end{array}$ \\
\hline & \multicolumn{5}{|c|}{$\begin{array}{l}\text { Human interferences } \\
\text { er pollution, artifiical waters, channels, pipes etc.) }\end{array}$} \\
\hline \multirow[t]{2}{*}{ Vectors } & $\begin{array}{c}\text { Migrating } \\
\text { animals (fish, } \\
\text { whales, birds), } \\
\text { Drifting animals, } \\
\text { Particles, wood } \\
\text { (resting stages) }\end{array}$ & $\begin{array}{c}\text { Zooplankton, } \\
\text { Fish, } \\
\text { Drifting animals, } \\
\text { Organic/inorganic } \\
\text { particles }\end{array}$ & $\begin{array}{c}\text { Zooplankton, } \\
\text { Fish, } \\
\text { Organic/inorganic } \\
\text { particles }\end{array}$ & $\begin{array}{c}\text { Viruses, } \\
\text { Phytoplankton, } \\
\text { Zooplankton, } \\
\text { Organic/inorganic } \\
\text { particles }\end{array}$ & $\begin{array}{l}\text { Genes, } \\
\text { Metabolites }\end{array}$ \\
\hline & \multicolumn{5}{|c|}{$\begin{array}{l}\text { Human-made } \\
\text { (Waste water, trash including micro-/ macroplastics, boats, etc.) }\end{array}$} \\
\hline \multirow[t]{2}{*}{$\begin{array}{l}\text { Temporal } \\
\text { Dynamics }\end{array}$} & $\begin{array}{c}\text { Climate } \\
\text { (summer-winter, } \\
\text { wet-dry season, } \\
\text { etc.) }\end{array}$ & $\begin{array}{l}\text { "Flood pulse } \\
\text { concept", } \\
\text { Permanent vs. } \\
\text { temporary }\end{array}$ & $\begin{array}{l}\text { Algal blooms, } \\
\text { River plumes, } \\
\text { Litter input, } \\
\text { Terrestrial runoff, } \\
\text { ocean upwelling, } \\
\text { Permanent vs. } \\
\text { temporary }\end{array}$ & $\begin{array}{c}\text { Organismic } \\
\text { processes and } \\
\text { behaviour, } \\
\text { blooms, } \\
\text { exudation, } \\
\text { diurnal cycles }\end{array}$ & $\begin{array}{l}\text { Organismic } \\
\text { activity, growth } \\
\text { rates }\end{array}$ \\
\hline & \multicolumn{5}{|c|}{$\begin{array}{l}\text { Human activities } \\
\text { (Water pollution, water substraction, damming, etc.) }\end{array}$} \\
\hline
\end{tabular}


Figure 1: Phylogeny of aquatic fungi. Fungal tree of life including all fungal phyla (modified after REF. ${ }^{45,160}$ ), illustrating the morphological, phylogenetical, and ecological diversity of aquatic fungi. In blue are depicted, phyla, subphyla and for Pezizomycotina classes which contain typical aquatic fungi. The early diverging lineages at the base of the fungal tree have an aquatic origin, displaying morphological adaptations in form of zoo-or amoeboid spores that are adapted to dispersal in aquatic habitats. Many of them can be classified within the ecological group of Phycomycetes, associated as saprophytes or parasites with pollen, macrophytes, algae and phytoplankton. Zoopagomycota and Kickxellomycota include amoebophagous and predatory fungi and Trichomycetes, a diverse ecological group of obligate endosymbionts in the gut of many aquatic insect. The polyphyletic aquatic hyphomycetes, associated with leaf litter, decaying macrophytes and driftwood in freshwater and marine habitats, are mainly found within Ascomycota and fewer within Basidiomycota. Aquatic hyphomycetes most probably have evolved from terrestrial fungi and morphological adaptations (e.g. drifting, branched conidiospores, ascospores with sticky sheaths) to colonize aquatic habitats and attach to submerged substrates. This group contains also species that can alternate their life cycle between aquatic and terrestrial habitats (i.e. aero-aquatic fungi). A variety of single celled yeast and yeast-like fungi within Ascomycota and Basidiomycota have been found in freshwater and marine environments, ranging from parasites of invertebrates to extremophilic yeast from Antarctic sea ice. Most of the Basidiomycota species are yeast-like species with the wondrous exception of the wood degrading basidiomycete Psathyrella aquatica, which is the first discovered underwater species with true gills.

Figure 2: Natural environments for aquatic fungi. This conceptual graph shows diverse habitats, stretching from high montane lentic habitats down to the deep open ocean, using a landscape perspective. The spatio-temporal gradients in relation to factors such as altitude, depth, input of terrestrial organic matter, fungal abundance, evolutionary age, and residence time of the water flow are highlighted. The panel presents, for each habitat, the current status of knowledge on aquatic fungi in relation to their diversity, function, interactions, and ecological role. This knowledge status is presented in a semi-quantitative scale.

Figure 3: Artificial habitats for aquatic fungi. This conceptual graph shows diverse artificial habitats for aquatic fungi resulting from human intervention in landscapes. Humans have transformed natural landscapes by creating a series of new artificial niches, which have been colonized by fungi. Distinctive communities of aquatic fungi can be found in human-transformed habitats such as cities, houses, industries, farming (terrestrial and aquatic), mines, and several other aquatic microhabitats within them. However, the effects of these human interventions on aquatic fungal communities remain largely unknown. We foresee a growing interest in the study of aquatic mycology in urban environments, considering aspects such as diversity, but also the consequences of altering their ecological roles in relation to foodwebs and biogeochemical cycles.

Figure 4: Images of saprophytic and symbiotic (dark matter) fungal interactions with different components of the aquatic foodweb. Fungi are visualized by fluorescent staining with calcofluor white (blue) and/or wheat germ agglutinin Alexa Fluor ${ }^{\circledR} 488$ conjugate (green). Images a-c display saprophytic fungi on different OM 
substrates: yeast-like fungal spores associated to lake snow aggregates (a), chytrid fungi colonizing and degrading the cellulosic theca of a dinoflagellate (b) and chitinous carapace of zooplankton (c). Images d-f display parasitic fungi on bacteria; chytrid fungi parasitizing the largest freshwater heterotrophic bacterium Achromatium oxaliferum (d) and the phototrophic cyanobacterium Dolichospermum sp. (e), unknown "dark matter fungi" parasitizing cyanobacterial filaments (f). The parasitic nature of the interaction can be inferred by the cell death/loss of autofluorescence of the host cells. Images g-i display "dark matter fungi" and interactions; unidentified fungi attached to the cyanobacterium Dolichospermum sp. (g), unidentified fungal spores that presumably have parasitized a diatom (loss of autofluorescence) (h), a potential hyperparasitic interaction between unidentified fungi (green) and a chytrid fungi (blue) that parasitizes the diatom Fragilaria crotonensis.

Note that in image (b) the blue color represents the dinoflagellate theca which has been stained by the cellulose binding calcofluor white stain, whereas the green color represents fungi which have been stained by the more specific chitin binding Wheat germ agglutinin stain. White scale bar $=10 \mu \mathrm{m}$, except in picture c scale bar $=50 \mu \mathrm{m}$.

Figure 5: Ecological role of aquatic fungi. This conceptual model shows different processes by which aquatic fungi transform and incorporate allochthonous and autochtonous OM into the foodweb. Three major processes are highlighted: (a) Mycoloop, (b) MycoFlux and (c) Benthic Shunt. (a) The Mycoloop has been well described and refers to parasitic fungi rendering inedible phytoplankton edible to zooplankton grazers either by fragmentation of the phytoplankton or by producing zoospores. (b) The Mycoflux has not been specifically named before and describes any fungal interaction leading to aggregation or disintegration of organic matter. The consequences are still largely unknown, but it is likely that they greatly affect the aquatic carbon pump efficiency. (c) The Benthic Shunt has only been described for lakes and it refers to fungal colonization of organic litter rendering it palatable for macrozoobenthos on the sediment. The macrozoobenthos provides an excellent food for higher trophic levels such as fish and thus increases the trophic transfer efficiency of the aquatic foodweb. 


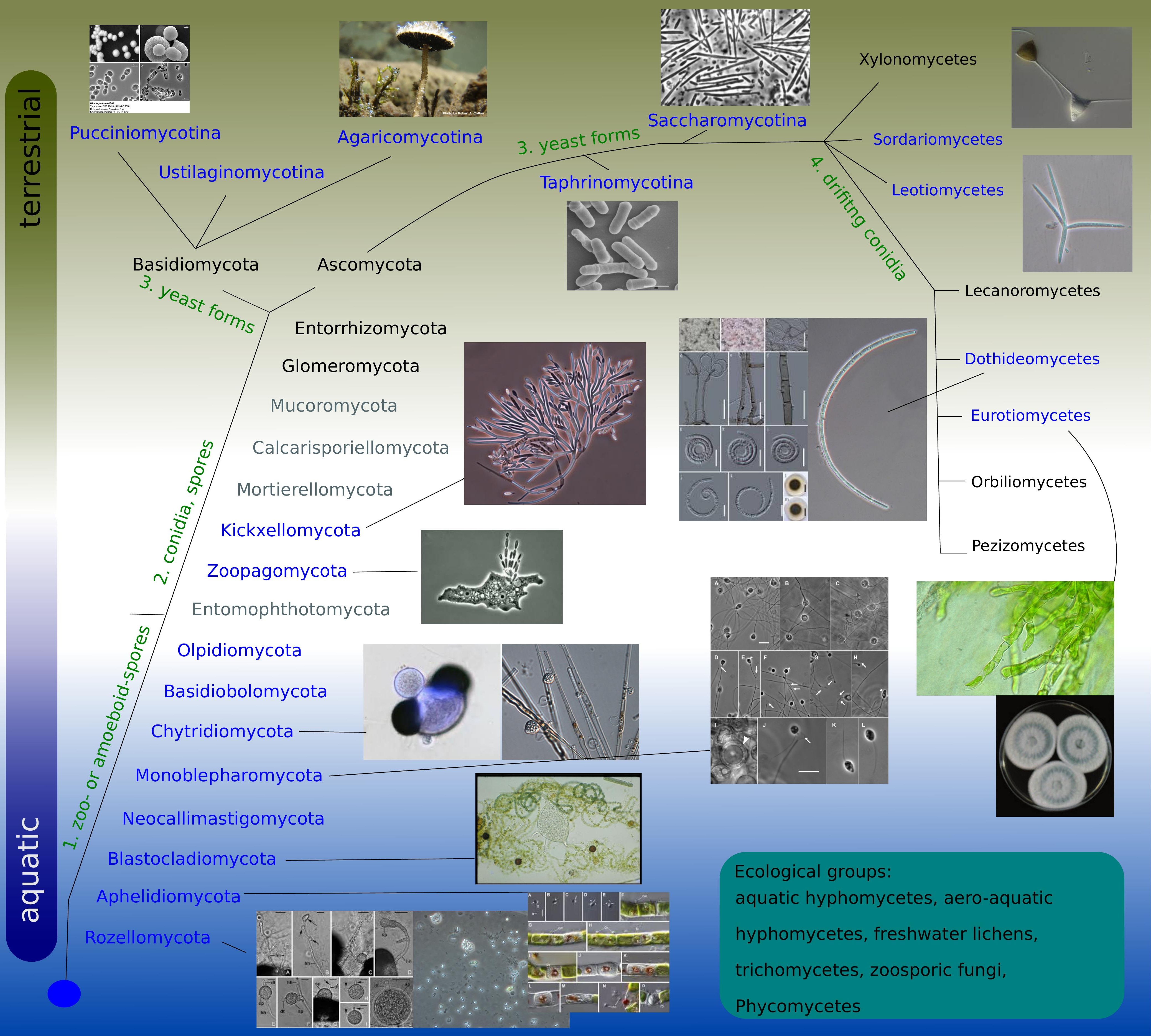




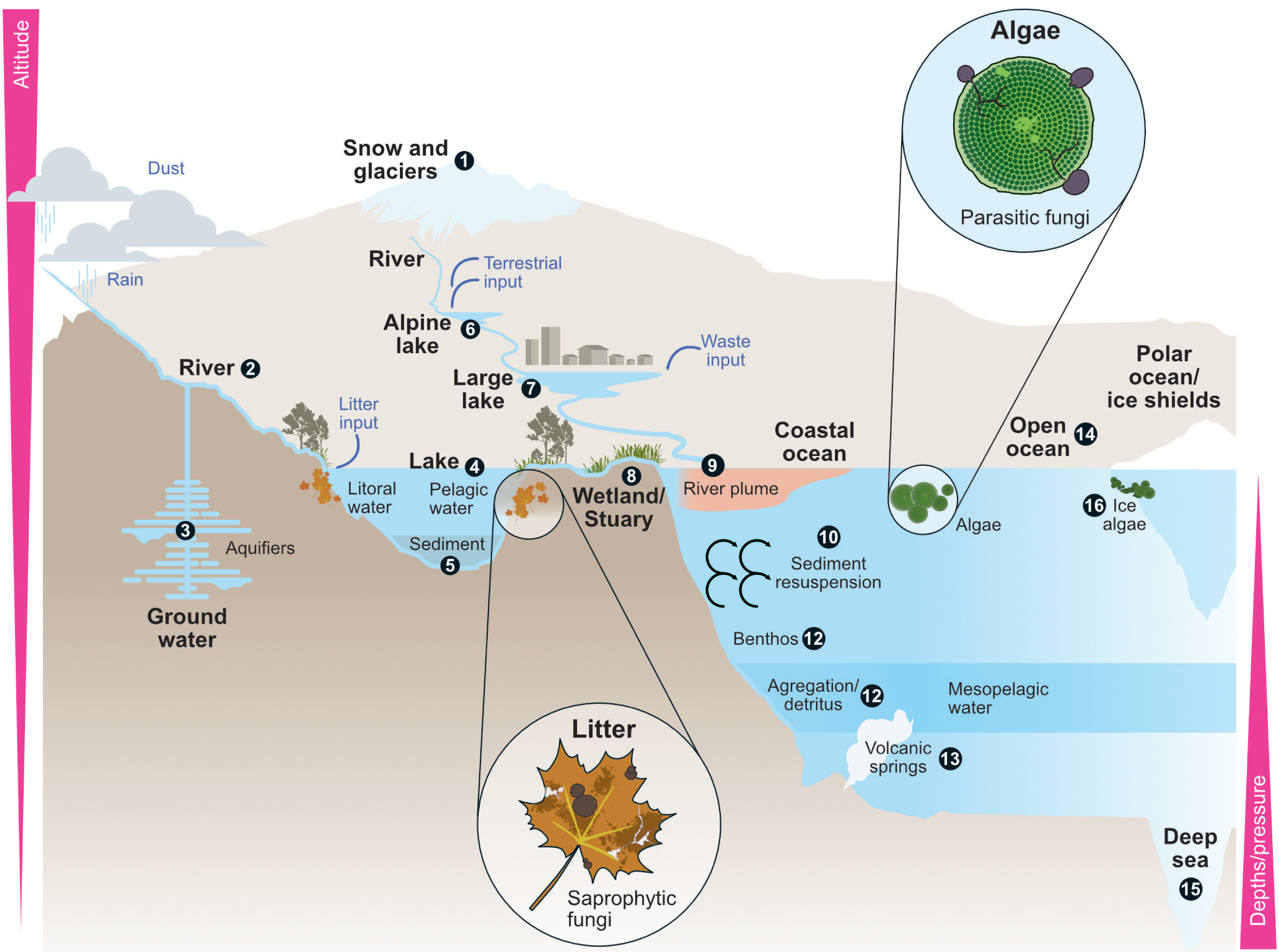

Coarse POM filamentous fungi

\section{Terrestrial input + nutrients}

Residence time + salinity

\section{Knowledge}

\section{on aquatic} fungi

1. Diversity-

2. Functions

3. Interactions

4. Ecological role-

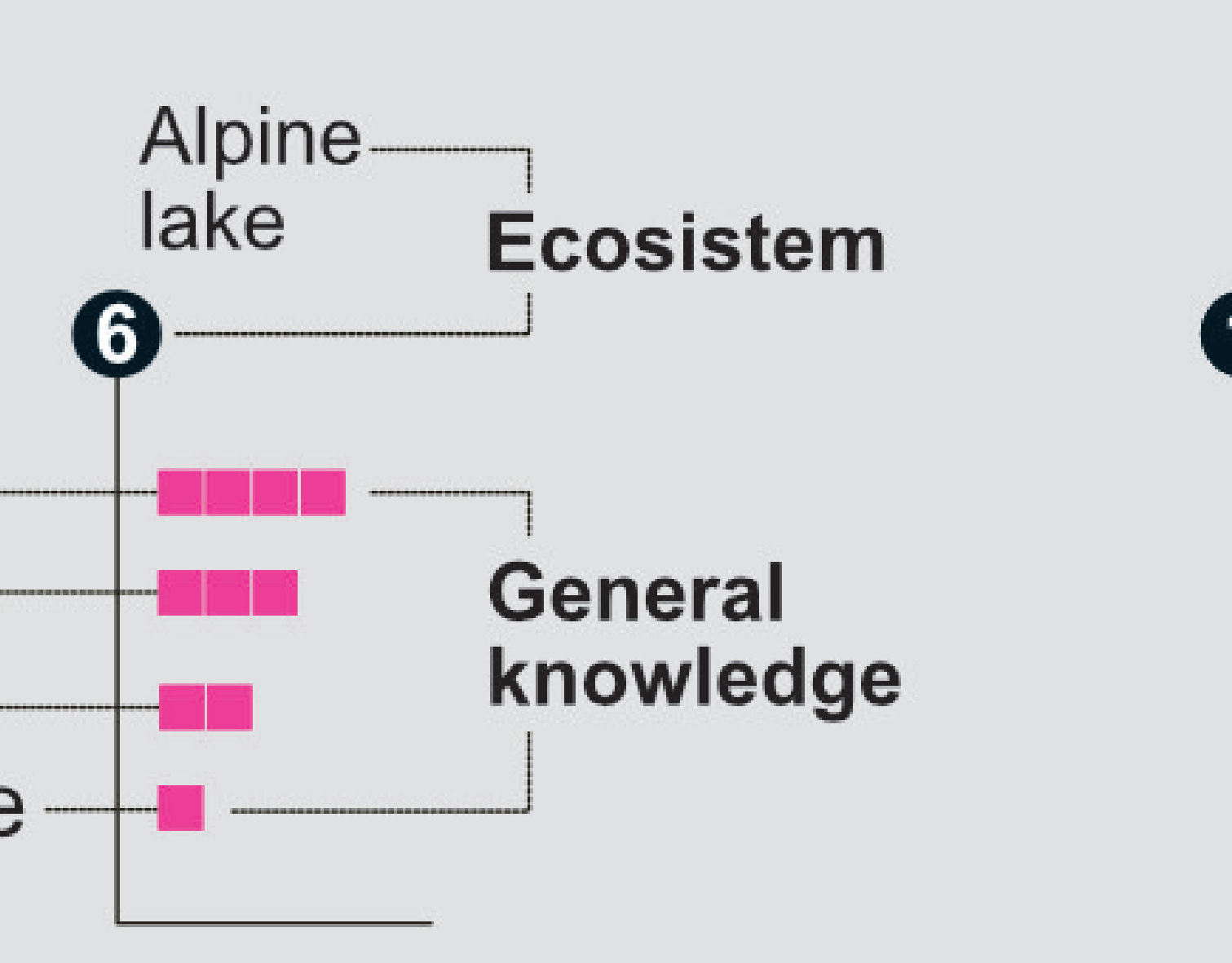

\begin{tabular}{ll}
$\begin{array}{ll}\text { Wetland/ } \\
\text { stuary }\end{array}$ & $\begin{array}{l}\text { River } \\
\text { plume }\end{array}$ \\
8 & $\mathbf{9}$ \\
\hdashline
\end{tabular}

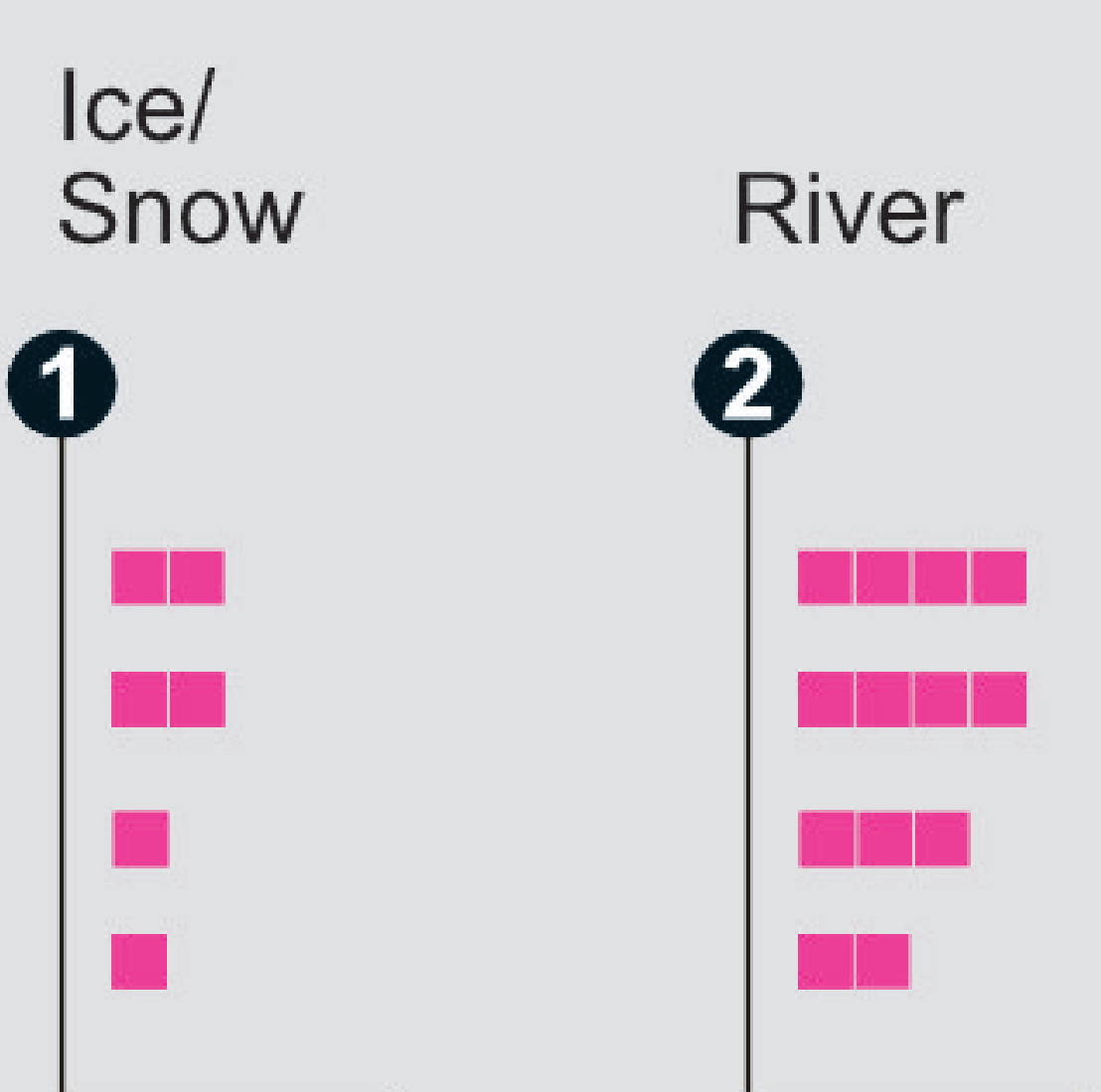

Sediment

resuspension Benthos

\section{(10)}

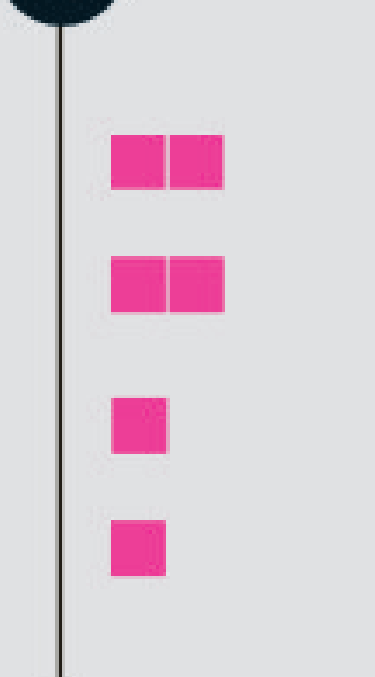

(11)

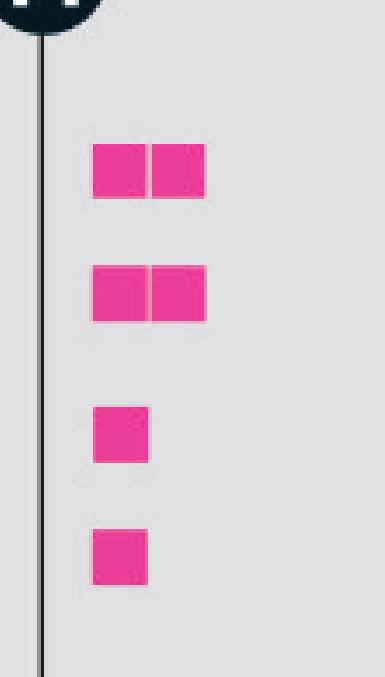

\section{Grownd}

water

3

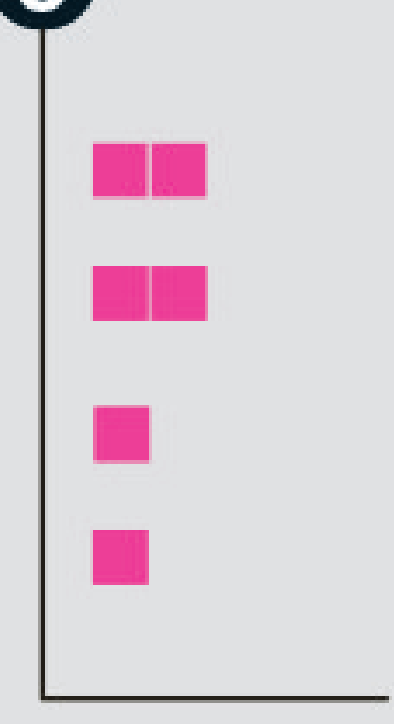

Agregation/ detritus

(12)

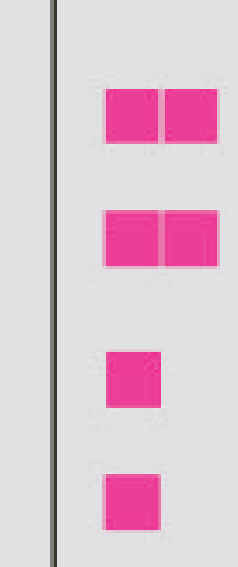

\section{Lake/ Pelagic}

water

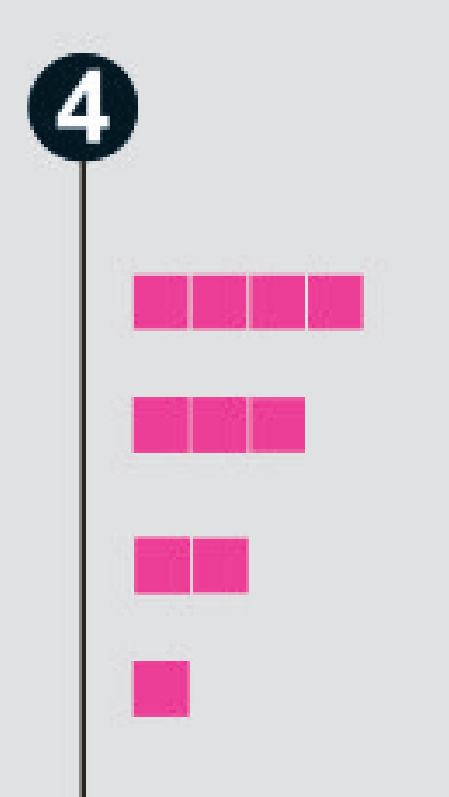

5

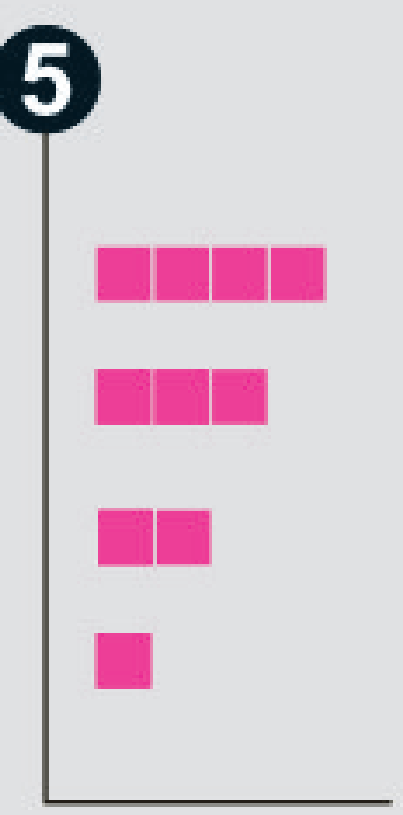

Volcanic springs

(13) 


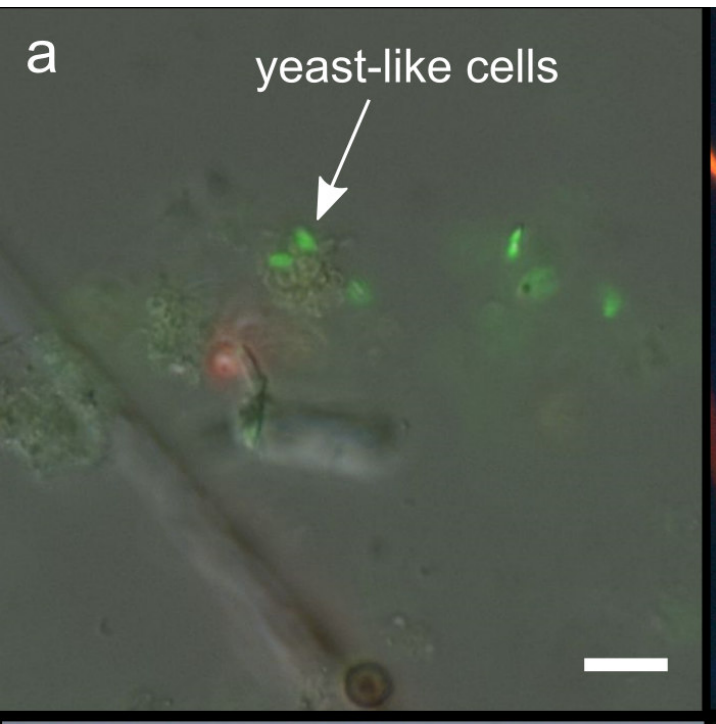

d empty Achromatium cell

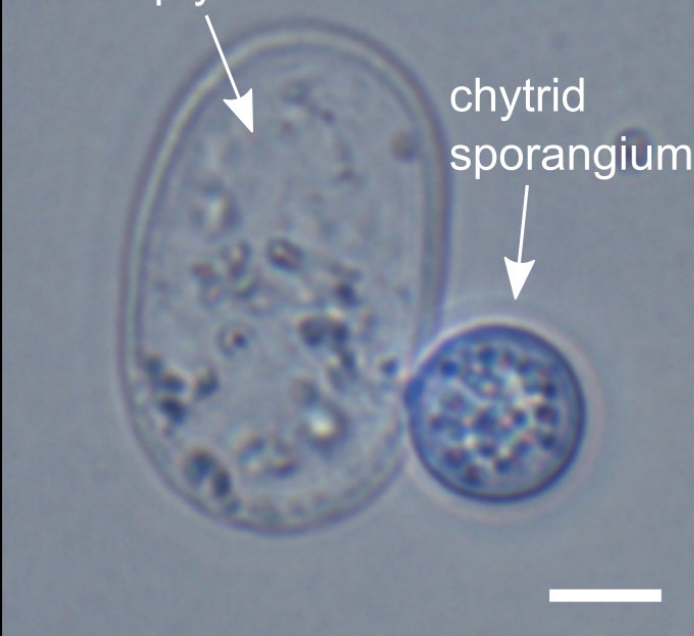

e rhizoid inside empty chytrid $f$ host cell
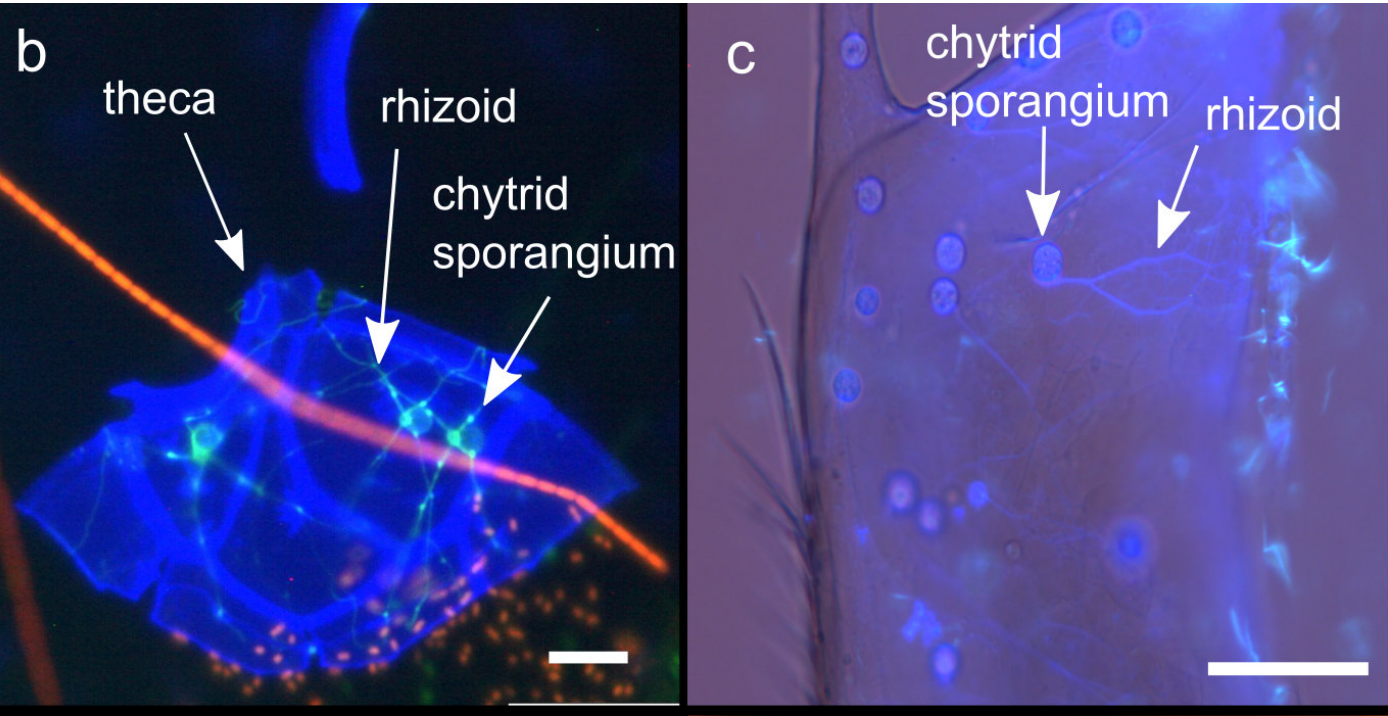
sporangium
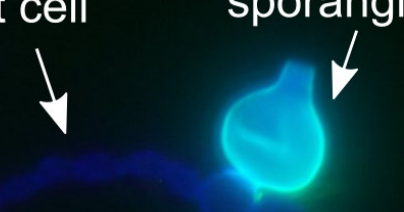

g

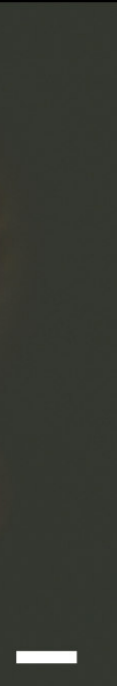

h<smiles>[3H]C</smiles>

uninfected host cell

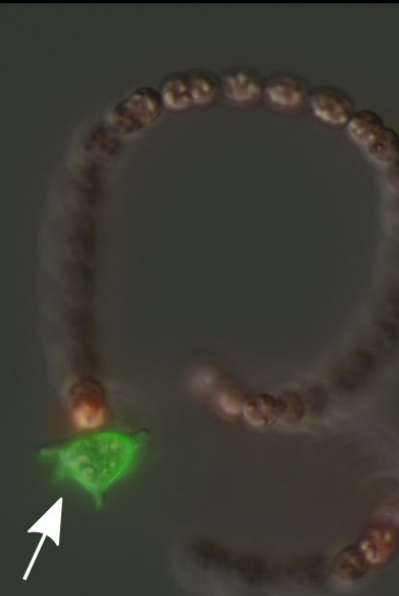

sporangium? 


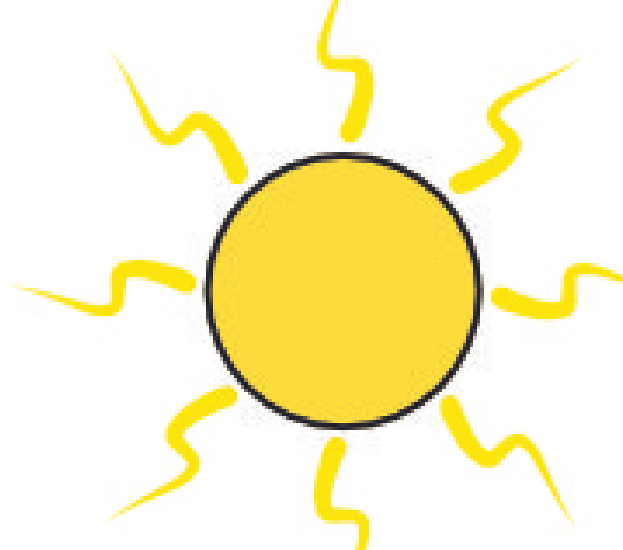

\section{Autochthonous \\ OM}

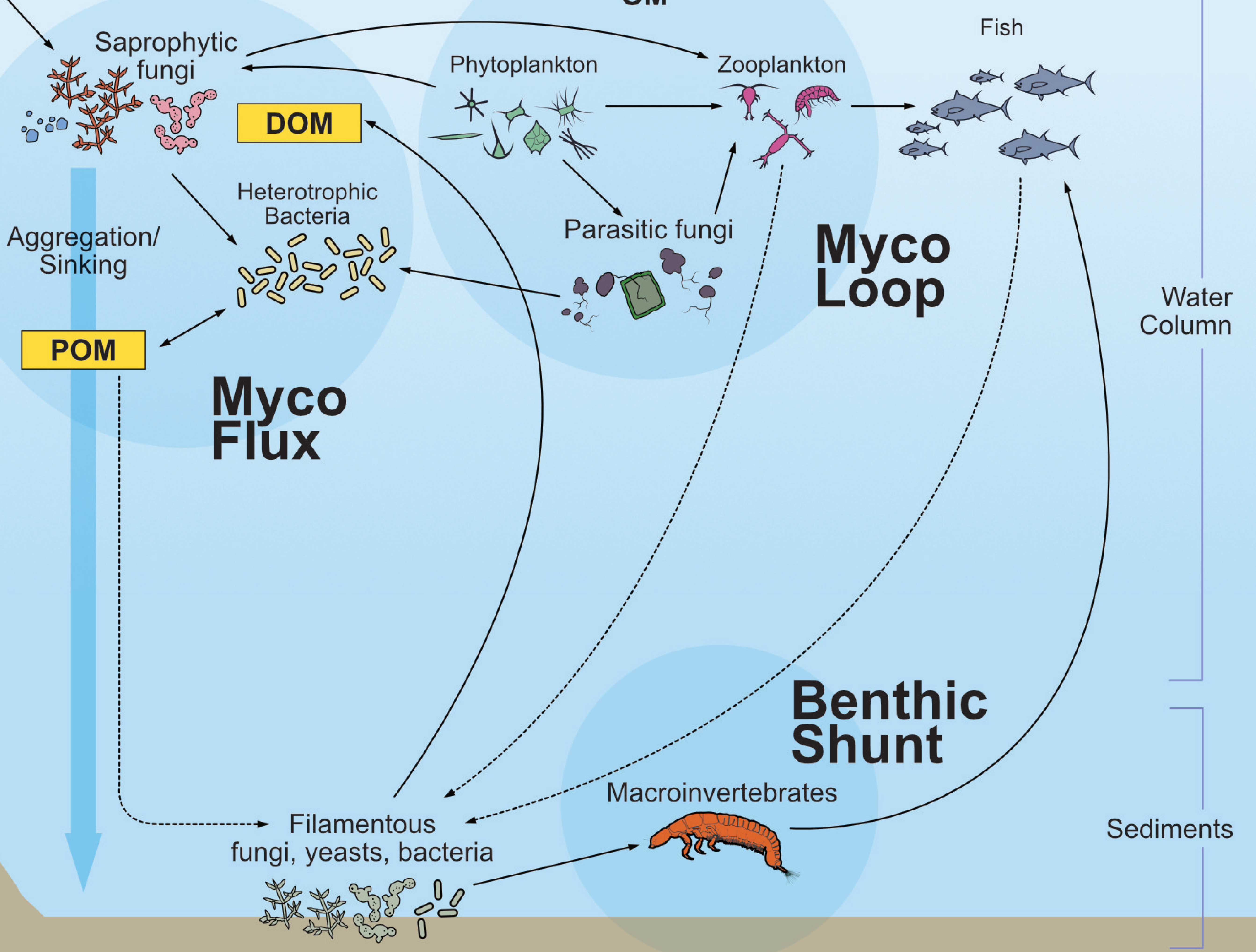

